\title{
Gammaproteobacterial methanotrophs dominate methanotrophy in aerobic and anaerobic layers of boreal lake waters
}

\author{
Antti J. Rissanen ${ }^{1,2, *}$, Jatta Saarenheimo ${ }^{2}$, Marja Tiirola ${ }^{2}$, Sari Peura ${ }^{3}$, \\ Sanni L. Aalto ${ }^{2}$, Anu Karvinen ${ }^{4}$, Hannu Nykänen ${ }^{2,5}$ \\ ${ }^{1}$ Tampere University of Technology, Laboratory of Chemistry and Bioengineering, PO Box 527, 33101 Tampere, Finland \\ ${ }^{2}$ University of Jyväskylä, Department of Biological and Environmental Science, PO Box 35, 40014 Jyväskylä, Finland \\ ${ }^{3}$ Swedish University of Agricultural Sciences, Department of Forest Mycology and Plant Pathology, \\ Science for Life Laboratory, PO Box 7026, 75007 Uppsala, Sweden \\ ${ }^{4}$ University of Eastern Finland, Department of Environmental and Biological Sciences, PO Box 111, 80101 Joensuu, Finland \\ ${ }^{5}$ University of Eastern Finland, Department of Environmental and Biological Sciences, PO Box 1627, 70211 Kuopio, Finland
}

\begin{abstract}
Small oxygen-stratified humic lakes of the boreal zone are important sources of methane to the atmosphere. Although stable isotope profiling has indicated that a substantial part of methane is already oxidized in the anaerobic water layers in these lakes, the contributions of aerobic and anaerobic methanotrophs in the process are unknown. We used next-generation sequencing of mcrA and 16S rRNA genes to characterize the microbial communities in the water columns of 2 boreal lakes in Finland, Lake Alinen-Mustajärvi and Lake Mekkojärvi, and complemented this with a shotgun metagenomic analysis from Alinen-Mustajärvi and an analysis of pmoA genes and 16S rRNA, mcrA, and pmoA transcripts from Mekkojärvi. Furthermore, we tested the effect of various electron acceptors and light on methane oxidation $\left({ }^{13} \mathrm{C}-\mathrm{CH}_{4}\right.$ labeling $)$ in incubations of water samples collected from the lakes. Aerobic gammaproteobacterial methanotrophs (order Methylococcales) exclusively dominated the methanotrophic community both above and below the oxycline in the lakes. A novel lineage within Methylococcales, Candidatus Methyloumidiphilus alinensis, defined here for the first time, dominated in Alinen-Mustajärvi, while methanotrophs belonging to Methylobacter were more abundant in Mekkojärvi. Light enhanced methane oxidation in the anoxic water layer, while alternative electron acceptors $\left(\mathrm{SO}_{4}{ }^{2-}, \mathrm{Fe}^{3+}, \mathrm{Mn}^{4+}\right.$, and anthraquinone-2,6-disulfonate), except for $\mathrm{NO}_{3}{ }^{-}$, suppressed the process. Our results suggest that oxygenic photosynthesis potentially fuels methanotrophy below the aerobic water layers in methane-rich boreal lakes. Furthermore, incubation results, together with the detection of denitrification genes from metagenome-assembled genomes of gammaproteobacterial methanotrophs, imply that boreal lake methanotrophs may couple methane oxidation with $\mathrm{NO}_{\mathrm{x}}{ }^{-}$reduction in hypoxic conditions.
\end{abstract}

KEY WORDS: Methanotroph · Methane oxidation - Boreal lake · Water column · Shotgun metagenomics $\cdot 16 \mathrm{~S} \mathrm{rRNA} \cdot \mathrm{mcr} A \cdot \operatorname{pmoA}$

\section{INTRODUCTION}

The concentration of atmospheric methane $\left(\mathrm{CH}_{4}\right)$, a critical greenhouse gas, has increased substantially since industrialization, with current total emis-

${ }^{*}$ Corresponding author: antti.rissanen@tut.fi sions in the order of 500 to $600 \mathrm{Tg} \mathrm{yr}^{-1}$ (Kirschke et al. 2013). Roughly $50 \%$ of these emissions stem from natural sources (Kirschke et al. 2013), mostly produced by archaea in methanogenesis, the final step in the anaerobic degradation of organic matter

() The authors 2018. Open Access under Creative Commons by Attribution Licence. Use, distribution and reproduction are unrestricted. Authors and original publication must be credited. 
(Conrad 1999). Although lakes occupy only $3.7 \%$ of the global non-glaciated land area (Verpoorter et al. 2014), their $\mathrm{CH}_{4}$ emissions are estimated to be as high as 6 to $24 \%$ of the total natural $\mathrm{CH}_{4}$ release (Bastviken et al. 2004, 2011). The numerous lakes and ponds in the northern areas (north of $50^{\circ} \mathrm{N}$ ) with annual $\mathrm{CH}_{4}$ emissions of $\sim 16.5 \mathrm{Tg}$ (6 to $7 \%$ of natural release) are especially significant components of the global $\mathrm{CH}_{4}$ budget (Wik et al. 2016). Thus, knowledge about $\mathrm{CH}_{4}$ cycling in lakes, especially in northern areas, is essential to better constrain its global input and will ultimately aid in predicting climate change.

$\mathrm{CH}_{4}$ emissions from natural ecosystems are largely regulated by aerobic oxidation by methane oxidizing bacteria (MOB), utilizing $\mathrm{O}_{2}$ as an electron acceptor (EA) (Hanson \& Hanson 1996), or through anaerobic oxidation of methane (AOM) by anaerobic methanotrophic archaea (ANME archaea), utilizing alternative inorganic $\left(\mathrm{NO}_{3}{ }^{-}, \mathrm{SO}_{4}{ }^{2-}, \mathrm{Mn}^{4+}\right.$ or $\mathrm{Fe}^{3+}$ ) or organic EAs (e.g. humic acids) (Beal et al. 2009, Knittel \& Boetius 2009, Haroon et al. 2013, Ettwig et al. 2016, Scheller et al. 2016). In addition, bacteria of the phylum NC10 may gain oxygen for the oxidation of $\mathrm{CH}_{4}$ in anaerobic conditions using the nitric oxide dismutase enzyme (Ettwig et al. 2010). Some methanogens also oxidize small amounts of $\mathrm{CH}_{4}$ without external EAs during trace methane oxidation due to enzymatic backflux (Moran et al. 2005, Timmers et al. 2017). While AOM coupled with $\mathrm{SO}_{4}{ }^{2-}$ reduction by ANME archaea is an efficient $\mathrm{CH}_{4}$ sink in oceanic sediments and waters (Knittel \& Boetius 2009), a variety of EAs, i.e. $\mathrm{SO}_{4}{ }^{2-}$, $\mathrm{Fe}^{3+}$, and $\mathrm{NO}_{3}{ }^{-} / \mathrm{NO}_{2}{ }^{-}$, have been shown to be important drivers of the AOM process in freshwater sediments (Sivan et al. 2011, Deutzmann et al. 2014, á Norði \& Thamdrup 2014, Timmers et al. 2016). However, recent geochemical and microbiological evidence from water columns of oxygen-stratified lakes (i.e. lakes with a temporary or permanently anoxic hypolimnion) of the temperate zone strongly suggests that aerobic MOBs dominate $\mathrm{CH}_{4}$ oxidation in both oxic and anoxic water layers (BiderrePetit et al. 2011, Blees et al. 2014, Milucka et al. 2015, Oswald et al. 2015, 2016a,b). Aerobic MOBs were also recently seen to dominate anaerobic $\mathrm{CH}_{4}$ oxidation in sub-arctic and temperate lake sediments (Bar-Or et al. 2017, Martinez-Cruz et al. 2017). Under oxygen limitation, MOBs may efficiently use the limited $\mathrm{O}_{2}$ to activate $\mathrm{CH}_{4}$ and are suggested to further support their metabolism by fermentation (Kalyuzhnaya et al. 2013) or by anaerobic respiration using alternative EAs, i.e. $\mathrm{NO}_{3}{ }^{-}$,
$\mathrm{NO}_{2}{ }^{-}$and $\mathrm{Fe}$ and $\mathrm{Mn}$ oxides (Kits et al. 2015a,b, Oswald et al. 2016b). Recently, it has been suggested that in situ oxygen production by photosynthetic algae (Milucka et al. 2015) or episodic oxygen introduction, events from the surface waters (Blees et al. 2014) could fuel MOBs in the anoxic waters. However, indirect evidence from lake sediments suggests that MOBs could also drive AOM independently of any external $\mathrm{O}_{2}$ source (Bar-Or et al. 2017, Martinez-Cruz et al. 2017).

A large number of small, shallow, brown-water lakes characterize the arctic and boreal regions (Kortelainen 1993, Downing et al. 2006). During summer, many of these lakes are steeply stratified with respect to temperature and chemical properties (including oxygen) (Salonen et al. 1984). Similar to lakes in the temperate zone, $\mathrm{CH}_{4}$ accumulates in the anoxic hypolimnion (Houser et al. 2003, Kankaala et al. 2007), and $\mathrm{CH}_{4}$ oxidation taking place in the water column acts as an efficient $\mathrm{CH}_{4}$ sink (Kankaala et al. 2006, Peura et al. 2012). In fact, isotopic profiling shows that a substantial part of $\mathrm{CH}_{4}$ oxidation already takes place in the anoxic water phase (Peura et al. 2012, Nykänen et al. 2014). However, clone library analyses of the mcrA gene coding for archaeal methyl co-enzyme $\mathrm{M}$ reductase (Milferstedt et al. 2010, Youngblut et al. 2014) and a recent shotgun metagenomic analysis (Peura et al. 2015), although with modest sequencing depth, did not detect any AOM organisms in the anoxic waters of humic lakes. Furthermore, analyses targeting bacterial biomarkers have shown that MOBs constitute a significant part of the bacterial community in the anoxic waters of boreal lakes, overlapping with the strictly anaerobic Chlorobium (Taipale et al. 2009, Peura et al. 2012, Garcia et al. 2013, Schiff et al. 2017). Yet, the contributions of aerobic $\mathrm{CH}_{4}$ oxidation and AOM in the water columns of boreal lakes remain unresolved.

We studied the contribution of aerobic $\mathrm{CH}_{4}$ oxidation and AOM in water columns of 2 boreal oxygenstratified lakes by geochemical profiling and by conducting water sample incubations amended with ${ }^{13} \mathrm{C}$-labeled $\mathrm{CH}_{4}$ and various EAs. $\mathrm{CH}_{4}$-oxidizing microbial communities were studied by next-generation sequencing (NGS) of pmoA (coding for particulate methane monooxygenase Subunit a of aerobic MOBs), mcrA, and 16S rRNA genes and their RNA transcripts, and by shotgun metagenomics. We hypothesized that aerobic MOBs dominate the methanotrophic community as well as $\mathrm{CH}_{4}$ oxidation below the oxycline (oxic-anoxic interface) of water column of these boreal, $\mathrm{CH}_{4}$-rich lakes. 


\section{MATERIALS AND METHODS}

\section{Study lakes and sampling}

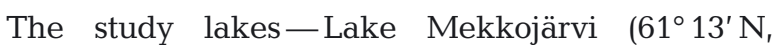
$25^{\circ} 8^{\prime} \mathrm{E}$ ) (area $0.004 \mathrm{~km}^{2}$, max. depth $4 \mathrm{~m}$, dissolved organic carbon [DOC] concentration $\sim 30 \mathrm{mg} \mathrm{C}^{-1}$ ), and Lake Alinen-Mustajärvi (61 ${ }^{\circ} 12^{\prime} \mathrm{N}, 25^{\circ} 06^{\prime} \mathrm{E}$ ) (area $0.007 \mathrm{~km}^{2}$, max depth $6.5 \mathrm{~m}$, DOC $\sim 10 \mathrm{mg} \mathrm{Cl}^{-1}$ ) -are small humic headwater lakes located in southern Finland. The lakes are usually ice-free from early May to mid-November and spring meromictic, i.e. the whole water column turns over in autumn but only partially in spring. Before the autumn overturn, the lakes are steeply stratified with respect to temperature and oxygen. For example, the oxycline was at 1 and $2 \mathrm{~m}$ depths in Mekkojärvi and Alinen-Mustajärvi, respectively, during summer stratification in 2009 (Karhunen et al. 2013). Photosynthetically active radiation (PAR), during a bright summer day, decreases from 107.5 to $0.1 \mu \mathrm{mol}$ photons $\mathrm{m}^{-2} \mathrm{~s}^{-1}$ between 1.5 and $5.5 \mathrm{~m}$ depth in Alinen-Mustajärvi; while in Mekkojärvi, it decreases from 96.4 to $0.5 \mu \mathrm{mol}$ photons $\mathrm{m}^{-2} \mathrm{~s}^{-1}$ between 0.5 and $1.5 \mathrm{~m}$ depth (surface PAR is $1400 \mu \mathrm{mol}$ photons $\mathrm{m}^{-2} \mathrm{~s}^{-1}$ ) (Karhunen et al. 2013). Thus, the potential zone for oxygenic photosynthesis, i.e. where PAR exceeds $\sim 0.1 \mu \mathrm{mol}$ photons $\mathrm{m}^{-2} \mathrm{~s}^{-1}$ (Gibson 1985, Brand et al. 2016 ), can extend well below the oxycline, to $\sim 2 \mathrm{~m}$ in Mekkojärvi and $\sim 5.5 \mathrm{~m}$ in Alinen-Mustajärvi. Accordingly, there was chlorophyll a below the oxycline in both study lakes in July $2009\left(\sim 3 \mu \mathrm{g} \mathrm{l}^{-1}\right.$ at $2.5 \mathrm{~m}$ in Mekkojärvi, and $\sim 10 \mu \mathrm{g} \mathrm{l}^{-1}$ at $5.5 \mathrm{~m}$ in Alinen-Mustajärvi; Karhunen et al. 2013).

The lakes were sampled at their deepest points on 9 September 2013 for Alinen-Mustajärvi and 1 September 2014 for Mekkojärvi. Vertical $\mathrm{O}_{2}$ and temperature profiles were measured using a YSI model 55 dissolved oxygen instrument (Yellow Springs Instruments). The water for the analysis of vertical variation in microbial communities (via DNA- and RNA-based amplicon sequencing) and background variables were collected using a Limnos water sampler. The background variables included oxidationreduction potential (ORP), $\mathrm{pH}$, concentrations of $\mathrm{CH}_{4}, \mathrm{CO}_{2}$ and sulfide, and ${ }^{13} \mathrm{C} /{ }^{12} \mathrm{C}$ of dissolved inorganic carbon (DIC) for both lakes. In addition data was collected on total dissolved $\mathrm{Fe}$ and $\mathrm{Mn}$ for Mekkojärvi, and on ${ }^{13} \mathrm{C} /{ }^{12} \mathrm{C}$ of $\mathrm{CH}_{4}$ and concentrations of inorganic nutrients $\left(\mathrm{NO}_{3}{ }^{-}+\mathrm{NO}_{2}{ }^{-}, \mathrm{NH}_{4}{ }^{+}\right.$, $\left.\mathrm{PO}_{4}{ }^{2-}\right), \mathrm{SO}_{4}{ }^{2-}$, total $\mathrm{N}$, total $\mathrm{P}, \mathrm{DOC}$ and particulate organic carbon (POC) for Alinen-Mustajärvi. For $\mathrm{CH}_{4}$ oxidation experiments, water was collected from the epi- $(1.2 \mathrm{~m})$, meta- $(1.6 \mathrm{~m})$, and hypolimnion $(2.8 \mathrm{~m})$ in Mekkojärvi and at the depth with the lowest estimated PAR suitable for oxygenic photosynthesis (5.5 m) in Alinen-Mustajärvi. Furthermore, an additional sampling for shotgun metagenomic analyses of vertical variation in microbial communities in AlinenMustajärvi water column was conducted on 23 September 2013. See Supplement 1 at www.int-res. com/articles/suppl/a081p257_supp.pdf for a more detailed description of the sampling.

\section{In vitro determination of potential $\mathrm{CH}_{4}$ oxidation}

To test the effects of EAs on the anaerobic $\mathrm{CH}_{4}$ oxidation of Mekkojärvi, the collected samples (epilimnion: $\mathrm{n}=3$; metalimnion: $\mathrm{n}=9$; hypolimnion: $\mathrm{n}=9$ ) were divided into the treatments reported in Table 1. Each treatment included 2 replicates with ${ }^{13} \mathrm{C}$-labeled $\mathrm{CH}_{4}$ and 1 replicate with ${ }^{14} \mathrm{C}$-labeled $\mathrm{CH}_{4}$. Incubations took $21 \mathrm{~d}$. The bottles were positioned upside down, partially submerged in water to prevent air exposure of the caps, and gently shaken once a week during the incubation. The sampling for ${ }^{13} \mathrm{C}$-content of DIC, concentrations of $\mathrm{CH}_{4}$ and $\mathrm{CO}_{2}$, as well as DNA and RNA, was done once, on the last day of incubations.

For the incubations in Alinen-Mustajärvi, water was concentrated 20-fold, using tangential flow filtration. Anaerobic pre-incubation (dark, $7^{\circ} \mathrm{C}, \sim 6.5 \mathrm{mo}$ ), in gas-tight bottles amended with either ${ }^{13} \mathrm{C}^{-} \mathrm{CH}_{4}(6$ bottles), isotopically natural $\mathrm{CH}_{4}$ (3 bottles), or nothing (3 bottles), preceded the actual EA and light experiments of Alinen-Mustajärvi samples (Table 1). The samples for the temporal monitoring of $\mathrm{CH}_{4}$-concentration were taken 14 times, while those for ${ }^{13} \mathrm{C}$-DIC and sulfide were taken 5 and 2 times, respectively, from the bottles amended with ${ }^{13} \mathrm{C}_{-} \mathrm{CH}_{4}$ or normal $\mathrm{CH}_{4}$, during the 6.5 mo pre-incubation. One further sampling of $\mathrm{CH}_{4}$ and ${ }^{13} \mathrm{C}$-DIC was also performed thereafter from the pre-incubation bottles, after a total of 9 mo of incubation. Originally, the pre-incubation phase was done for DNA- and RNA-stable isotope probing (SIP) experiments. However, SIP failed due to insufficient nucleic acid extraction efficiency, which was tested from 3 freeze-dried samples (1 with isotopically natural $\mathrm{CH}_{4}$ and 2 with ${ }^{13} \mathrm{C}_{-} \mathrm{CH}_{4}$ ) sacrificed after $6 \mathrm{~d}$ of incubation and from $2 \mathrm{ml}$ subsamples collected after 5.5 mo of pre-incubation through septa and pelleted using centrifugation $(20000 \times g$ for $8 \mathrm{~min})$. However, the pelleted samples taken after 5.5 mo of pre-incubation (thus, 1 mo before the onset of the actual EA and light experiments) were used to 
Table 1. Details of $\mathrm{CH}_{4}$ oxidation experiments carried out in 2 boreal lakes in Finland. In Lake Mekkojärvi experiments, inorganic electron acceptors (EAs) consisted of a mixture of $5 \mathrm{mM} \mathrm{NO}_{3}{ }^{-}, 1 \mathrm{mM} \mathrm{SO}_{4}{ }^{2-}, 10 \mathrm{mM} \mathrm{Mn}^{4+}$, and $0.5 \mathrm{mM} \mathrm{Fe}^{3+}$; while $4 \mathrm{mM}^{2}$ disodium anthraquinone-2,6-disulfonate was used as an organic EA. The final column shows the number of replicates amended with ${ }^{13} \mathrm{C}$-labeled $\mathrm{CH}_{4}$. In addition, there were control treatments without ${ }^{13} \mathrm{C}$-labeled $\mathrm{CH}_{4}$ (see ${ }^{\prime} \mathrm{Materials}$ and methods')

\begin{tabular}{|c|c|c|c|c|c|}
\hline Lake & $\begin{array}{l}\text { Depth } \\
\text { zone }\end{array}$ & $\begin{array}{c}\text { Pre- } \\
\text { incubation }\end{array}$ & Treatments & $\begin{array}{l}\text { Conditions (light, } \\
\text { temperature, time) }\end{array}$ & No. \\
\hline Mekkojärvi & $\begin{array}{l}\text { Epilimnion } \\
\text { Metalimnion } \\
\text { Hypolimnion }\end{array}$ & $\begin{array}{l}\text { No } \\
\text { No } \\
\text { No }\end{array}$ & $\begin{array}{l}\mathrm{CH}_{4} \\
\mathrm{CH}_{4} \\
\mathrm{CH}_{4}+\text { inorg. EAs } \\
\mathrm{CH}_{4}+\text { org. EAs } \\
\mathrm{CH}_{4} \\
\mathrm{CH}_{4}+\text { inorg. EAs } \\
\mathrm{CH}_{4}+\text { org. EAs }\end{array}$ & Dark $,+10^{\circ} \mathrm{C}, 21 \mathrm{~d}$ & 2 \\
\hline Alinen-Mustajärvi & Hypolimnion & Yes $^{a}$ & $\begin{array}{l}\mathrm{CH}_{4} \\
\mathrm{CH}_{4}+1 \mathrm{mM} \mathrm{NO}_{3}^{-} \\
\mathrm{CH}_{4}+1 \mathrm{mM} \mathrm{SO}_{4}^{2-} \\
\mathrm{CH}_{4}+3 \mathrm{mM} \mathrm{Fe}^{3+} \\
\mathrm{CH}_{4}+1 \mathrm{~g} \mathrm{l}^{-1} \text { humic acid } \\
\mathrm{CH}_{4}+1 \mathrm{~g} \mathrm{l}^{-1} \text { humic acid }+3 \mathrm{mM} \mathrm{Fe}^{3+} \\
\mathrm{CH}_{4}+\mathrm{O}_{2} \\
\mathrm{CH}_{4} \\
\mathrm{CH}_{4}\end{array}$ & $\begin{array}{l}\text { Dark, }+6.1^{\circ} \mathrm{C}, 134 \mathrm{~d} \\
\\
\text { Dark }_{,}+6.1^{\circ} \mathrm{C}, 27 \mathrm{~d} \\
\text { Light }+6.1^{\circ} \mathrm{C}, 134 \mathrm{~d} \\
\text { Red light },+6.5^{\circ} \mathrm{C}, 134 \mathrm{~d}\end{array}$ & 5 \\
\hline
\end{tabular}

analyze the change in the bacterial community structure during the pre-incubation period.

The subsamples (altogether 63 vials), taken from one of the pre-incubation bottles that had been amended with isotopically natural $\mathrm{CH}_{4}$, were used in the actual experiments, which tested the effects of various EAs and light on the $\mathrm{CH}_{4}$ oxidation of AlinenMustajärvi hypolimnion samples. The vials were degassed (made anoxic) before the onset of the experiment. The 9 experimental treatments reported in Table 1 each included 5 and 2 replicate vials with ${ }^{13} \mathrm{C}$-labeled and isotopically natural $\mathrm{CH}_{4}$, respectively. The incubations lasted for $134 \mathrm{~d}$, except for the $\mathrm{O}_{2}$ treatment, which lasted for $27 \mathrm{~d}$. PAR, measured using a LI-185B Quantum/Radiometer/Photometer with Quantum Q sensor (both LI-COR), was adjusted to $\sim 0.3 \mu \mathrm{mol}$ photons $\mathrm{m}^{-2} \mathrm{~s}^{-1}$ at the surface of the incubation bottles in both light treatments to represent the lowest PAR thresholds previously reported for oxygenic photosynthesis, i.e. 0.09 to $0.34 \mu \mathrm{mol}$ photons $\mathrm{m}^{-2} \mathrm{~s}^{-1}$ (Gibson 1985, Brand et al. 2016) (Table 1). A red light was chosen since it penetrates furthest in brown-water lakes (Kirk 1983) and, thus, may best represent the light conditions in deep layers. Sampling for ${ }^{13} \mathrm{C}$-content of $\mathrm{CO}_{2}$ was done 4 times during the incubation period. To avoid $\mathrm{O}_{2}$ contamination of the samples, the incubations and injec- tions (using He-flushed syringes and needles) were always done submerged in water. See Supplement 1 for a detailed description of experiments in both study lakes.

The added EA concentrations in experiments of both study lakes were either similar to or lower than those in previous AOM studies of aquatic and wetland environments (Beal et al. 2009, Blazewicz et al. 2012). However, they were higher than in situ concentrations to ensure the detection of EA effects on $\mathrm{CH}_{4}$ oxidation.

\section{Concentration and stable isotope analyses}

The analysis of dissolved sulfide, $\mathrm{SO}_{4}{ }^{2-}$, nutrients, DOC, POC, Fe, and $\mathrm{Mn}$ is described in Supplement 1. Concentrations of $\mathrm{CH}_{4}$ and $\mathrm{CO}_{2}$ in the water column of both lakes, as well as in EA experiments of Mekkojärvi, were measured using a gas chromatograph (GC), as described in Ojala et al. (2011). $\mathrm{CH}_{4}$ during the pre-incubation period of AlinenMustajärvi samples was measured using a Perkin Elmer Clarus 500 GC with a flame-ionization detector (FID). The ${ }^{13} \mathrm{C} /{ }^{12} \mathrm{C}$ of $\mathrm{CH}_{4}$ was measured using Isoprime 100 isotope ratio mass spectrometer (IRMS) coupled with a trace gas pre-concentrator, while the 
${ }^{13} \mathrm{C} /{ }^{12} \mathrm{C}$ of DIC and $\mathrm{CO}_{2}$ was analyzed either with the same device (Mekkojärvi samples) or with a Thermo Finnigan GasBench II connected to an XP Advantage IRMS (Alinen-Mustajärvi samples), using the same in-house carbon standard $\left(\mathrm{CaCO}_{3}\right)$. Isotope results were expressed as $\delta^{13} \mathrm{C}$ values for water column data and as excess concentration of ${ }^{13} \mathrm{C}-\mathrm{CO}_{2}$ or ${ }^{13} \mathrm{C}$-DIC for incubations (i.e. the concentration of ${ }^{13} \mathrm{C}$ produced solely from the added ${ }^{13} \mathrm{C}$ $\mathrm{CH}_{4}$ ) according to Supplement 1.

The accumulation of excess ${ }^{13} \mathrm{C}-\mathrm{CO}_{2}$ or ${ }^{13} \mathrm{C}-\mathrm{DIC}$ was converted into production rates (nmol $\mathrm{l}^{-1} \mathrm{~d}^{-1}$ ). This was done as a simple end-point calculation for Mekkojärvi samples, assuming negligible concentration of excess ${ }^{13} \mathrm{C}$-DIC at the start of incubations. For Alinen-Mustajärvi, $\mathrm{CH}_{4}$ oxidation was considered to take place only in treatments that showed linear accumulation of ${ }^{13} \mathrm{C}-\mathrm{CO}_{2}$ in time through all the 4 time (sampling) points (linear regression, $\mathrm{p}<0.05$ ), while $\mathrm{CH}_{4}$ oxidation was regarded negligible for other treatments. The production rates of ${ }^{13} \mathrm{C}-\mathrm{CO}_{2}$ in Alinen-Mustajärvi samples were then calculated using the end-point approach, but for 3 time periods, covering the whole incubation period: (1) 0-6 d (treatment with $\mathrm{CH}_{4}+\mathrm{O}_{2}$ ) or 0-21 d (other treatments), (2) 6-9 d (treatment with $\mathrm{CH}_{4}+\mathrm{O}_{2}$ ) or 21$71 \mathrm{~d}$ (other treatments), and (3) 9-27 d (treatment with $\mathrm{CH}_{4}+\mathrm{O}_{2}$ ) or 71-134 d (other treatments).

\section{DNA- and RNA-based amplicon sequencing analyses}

The DNA and RNA of water column and EA experiment samples from Mekkojärvi were extracted from filters using the PowerWater RNA Isolation Kit (MO BIO Laboratories) according to the manufacturer's instructions. For Alinen-Mustajärvi, DNA was extracted from 1.2 to $4.5 \mathrm{mg}$ of freeze-dried water column biomass, using the PowerSoil DNA Isolation Kit (MO BIO). In addition, a phenol-chloroform and bead-beating protocol was used to extract DNA from the pelleted sample collected from the pre-incubation bottle of Alinen-Mustajärvi 1 mo before the water in the bottle was subjected to the EA and light experiments (Griffiths et al. 2000).

Bacterial communities were studied by using NGS of the bacterial 16S rRNA gene and 16S rRNA amplicons. Potential and active methanogenic/methanotrophic archaea were studied by using NGS of mcrA amplicons from DNA and mRNA, while methanotrophic bacteria were studied by targeting pmoA. Primers, PCR, reverse-transcriptase PCR (RT-PCR), preparation of NGS libraries, and the sequencing
(Ion Torrent ${ }^{\mathrm{TM}}$ Personal Genome Machine) are described in detail in Supplement 1.

Mothur (Schloss et al. 2009) was used in all subsequent sequence analyses, unless reported otherwise. Barcodes and primer sequences, as well as lowquality sequences (containing $\geq 1$ mismatch in primer or barcode sequences, ambiguous nucleotides, homopolymers longer than 8 nucleotides, and not fulfilling the quality parameters qwindowaverage $=20$ and qwindowsize $=10$ ) were removed. FrameBot (from the FunGene website, http://fungene.cme.msu.edu/ FunGenePipeline) (Fish et al. 2013, Wang et al. 2013) was used to correct frameshift errors in mcrA and pmoA reads.

Bacterial 16S rRNA gene sequences were aligned using Silva reference alignment (Release 119), while pmoA and mcrA were aligned using reference alignments retrieved from FunGene (http://fungene.cme. msu.edu/index.spr). Chimeric sequences, identified using Uchime (Edgar et al. 2011), were removed from each library, and a preclustering algorithm (Huse et al. 2010) was used to reduce the effect of sequencing errors. 16S rRNA sequences were assigned taxonomies with a naïve Bayesian classifier (bootstrap cutoff value $75 \%$ ) (Wang et al. 2007), using the Silva database (Release 128), and sequences classified as archaea, chloroplast, mitochondria, and eukaryota were removed. Taxonomic classification of the functional genes took place similarly but with recently constructed databases for mcrA (Rissanen et al. 2017) and pmoA (Dumont et al. 2014).

Sequences were divided into operational taxonomic units (OTUs) at a $97 \%$ similarity level for $16 \mathrm{~S}$ rRNA and at a $95 \%$ similarity level for mcrA and pmoA. Singleton OTUs (OTUs with only 1 sequence) were removed, and the data were normalized by subsampling to the same size, which was 1129 for 16S rRNA (average length 212 bp) for both lakes, 144 for pmoA ( 243 bp) for Mekkojärvi, and 696 and 310 for mcrA ( 243 bp) for Mekkojärvi and AlinenMustajärvi, respectively. Sequence variation was adequately covered in these libraries, as shown by Good's coverage, an estimate of the proportion of amplified gene amplicons represented by sequence libraries for each sample that varied from 0.84 to 0.99 for $16 \mathrm{~S}$ rRNA, 0.95 to 1 for $m c r A$, and 0.92 to 1 for pmoA. The size of 2 pmoA and 5 mcrA libraries fell below the above limits, and of these, only $3 \mathrm{mcr} A$ libraries (with >75 sequences) were included for further calculations of relative abundances of OTUs, while the others were discarded.

Methanotrophic OTUs belonging to Methylococcales in 16S rRNA and pmoA libraries were classified to 
genus level by searching their representative sequences against the NCBI nt/nr-database using standard nucleotide (blastn) and translated BLAST (blastx), respectively, as well as via phylogenetic tree analyses. Phylogenetic tree analyses, including representative sequences of OTUs, and database sequences of known Methylococcales were performed with Mothur-aligned nucleotide sequences for $16 \mathrm{~S}$ rRNA and ClustalW-aligned deduced amino acid sequences for $p m o A$ using the maximum likelihood algorithm (Jones-Taylor-Thornton [JTT] model for pmoA and the generalized time reversible [GTR] model for 16S rRNA) with 100 bootstraps in Mega 6.0 (Tamura et al. 2013). Besides analysing methanotrophs, bacterial 16S rRNA and 16S rRNA gene OTUs were classified into other functional groups based on previous literature. Cyanobacteria, as well as strictly anaerobic, anoxygenic phototrophic $\mathrm{H}_{2} \mathrm{~S}$, and $\mathrm{Fe}^{2+}$-oxidizing Chlorobium (Van Gemerden \& Mas 1995, Heising et al. 1999), were specifically analysed from both lakes. In addition, the higher depth resolution sampling in Alinen-Mustajärvi allowed the comparison of the depth distribution of methanotrophs with that of aerobic, i.e. nitrifying (Alawi et al. 2007) and $\mathrm{Fe}^{2+}$-oxidizing (Hedrich et al. 2011, MoyaBeltrán et al. 2014), and anaerobic, i.e. $\mathrm{SO}_{4}{ }^{2-}$-reducing (Postgate \& Campbell 1966, Finster 2008, Kuever 2014, Hausmann et al. 2016) and $\mathrm{Fe}^{3+}$-reducing (Lovley 2006), bacteria.

\section{Shotgun metagenomic analyses}

The samples for shotgun sequencing were taken from $0.2 \mu \mathrm{m}$ polycarbonate filters, and the DNA was extracted using the PowerSoil DNA Isolation Kit (MO BIO). The preparation of the shotgun metagenomic libraries and sequencing (paired-end sequencing on the Illumina HiSeq2500 platform) are described in detail in Supplement 1.

The sequencing produced a total of $120.5 \mathrm{~Gb}$ of sequence data. Reads were quality-filtered using Sickle (version 1.33; https://github.com/najoshi/sickle) and subsequently assembled with Ray (version 2.3.1) (Boisvert et al. 2010). Assembled contigs were cut into 1000 bp pieces and scaffolded with Newbler (454 Life Sciences, Roche Diagnostics). The mapping of the original reads to the Newbler assembly was done using Bowtie2 (version 2.15.0) (Langmead \& Salzberg 2012), while duplicates were removed using Picard tools (version 1.101; https://github.com/ broadinstitute/picard), and BEDTools (Quinlan \& Hall 2010) was used for computing coverage. The data were then normalized using the counts of 139 single copy genes as described previously (Rinke et al. 2013). The assembled contigs were binned with MetaBAT (version 0.26.3) (Kang et al. 2015) to reconstruct the genomes of the most abundant lake microbes, i.e. metagenome assembled genomes (MAGs). The quality of the MAGs was evaluated using CheckM (version 1.0.6) (Parks et al. 2015). The cut-offs for high-quality MAGs were set to $\geq 40 \%$ for completeness and $\leq 5 \%$ for contamination.

The raw reads from the shotgun sequencing were screened for methanotrophs using Kaiju (Menzel et al. 2016) with default settings against the complete NCBI RefSeq database. Furthermore, the functional potential of the metagenomes was assessed from the assembled data using the hidden Markov models (HMM) of the Pfam and TIGRFAM databases (Finn et al. 2007, Selengut et al. 2007) and HMMER3 software (version 3.1b2) (Durbin et al. 2002). The placement of the MAGs in the microbial tree of life was estimated using PhyloPhlAn (version 1.1.0) (Segata et al. 2013). All of the MAGs were also annotated using Prokka (version 1.11) (Seemann 2014). Furthermore, pmoA sequences of the methanotroph MAGs were analysed via phylogenetic tree analyses as explained above. In this study, the metagenomic analysis was focused solely on methanotrophs. A more general view on the metagenomic dataset will be given elsewhere (S. Peura et al. unpubl. data).

\section{Sequence data accession numbers}

Sequencing data were deposited to the NCBI Sequence Read Archive under study accession numbers SRP110764 for amplicon sequence data and SRP076290 for shotgun metagenomics data.

\section{Statistical analyses}

The differences in ${ }^{13} \mathrm{C}-\mathrm{CO}_{2}$ production rates between treatments in Alinen-Mustajärvi were examined separately for each of the 3 time periods during the incubation (Periods 1 to 3, see above), using a 1way analysis of variance $(p<0.05)$ followed by pairwise post-hoc tests, using the least significant difference (LSD) technique with Hochberg-Bonferronicorrected $\alpha$-values. The analyses were performed using IBM SPSS Statistics version 23. The results of Lake Mekkojärvi experiments were only interpreted visually, due to low sample size $(\mathrm{n}=2)$. 


\section{RESULTS}

\section{Physicochemical conditions in the water column of the study lakes}

The study lakes were acidic $(\mathrm{pH} \leq 6)$. The temperature stratification was stronger in Alinen-Mustajärvi than in Mekkojärvi (Figs. S1 \& S2A; all supplementary figures are available in Supplement 2 at www. int-res.com/articles/suppl/a081p257 supp.pdf). Both lakes were steeply oxygen-stratified. The oxycline, which divided the water column into oxic epilimnion and anoxic meta- and hypolimnion, was at $1.3 \mathrm{~m}$ from the surface in Mekkojärvi and at $2.3 \mathrm{~m}$ in Alinen-Mustajärvi (Fig. 1A,C). ORP decreased only very slightly in the metalimnion before reaching the redoxcline in the hypolimnion, where a drastic decrease in ORP took place (Fig. 1A,C). In Alinen-Mustajärvi, the change in ORP was accompanied by a decrease in $\mathrm{SO}_{4}{ }^{2-}$ and an increase in dissolved sulfide (Fig. S2A). In Mekkojärvi, sulfide was also much higher in the meta- and hypolimnion than in epilimnion, and both $\mathrm{Fe}$ and $\mathrm{Mn}$ increased towards the bottom (Fig. S1). Furthermore, there was vertical variation in $\mathrm{NO}_{3}{ }^{-}+\mathrm{NO}_{2}{ }^{-}, \mathrm{NH}_{4}$, total-N, $\mathrm{PO}_{4}{ }^{3-}$, total-P, DOC, and POC in Alinen-Mustajärvi (Fig. S2B,C).

In Mekkojärvi, the concentrations of $\mathrm{CH}_{4}$ and $\mathrm{CO}_{2}$, and $\delta^{13} \mathrm{C}$ of DIC were higher in the hypolimnion than in other layers (Fig. 1B). In Alinen-Mustajärvi, the concentration and $\delta^{13} \mathrm{C}$ of $\mathrm{CH}_{4}$ were stable in the epilimnion and in the upper parts of the metalimnion (Fig. 1D,E). However, $\mathrm{CH}_{4}$ concentration started to increase towards the bottom in the lower part of metalimnion. At the same time, $\delta^{13} \mathrm{C}_{\text {of }} \mathrm{CH}_{4}$ peaked in the lower part of metalimnion, then decreased considerably towards the upper part of the hypolimnion, and was at stable low levels below $5 \mathrm{~m}$ depth (Fig. 1D,E). $\mathrm{CO}_{2}$ concentration was quite stable in the upper part of the epilimnion, then increased gradually towards the middle part of the metalimnion, and was quite stable until $4.5 \mathrm{~m}$ depth in the hypolimnion. Below $4.5 \mathrm{~m}$ depth, a substantial increase in $\mathrm{CO}_{2}$ took place towards the bottom (Fig. 1D). In contrast, $\delta^{13} \mathrm{C}$ of DIC fluctuated in the water column, with lower values in the lower part of epilimnion and at the interface between meta- and hypolimnion, and higher values in the upper part of the epilimnion, in the middle of the metalimnion and at the bottom (Fig. 1D).
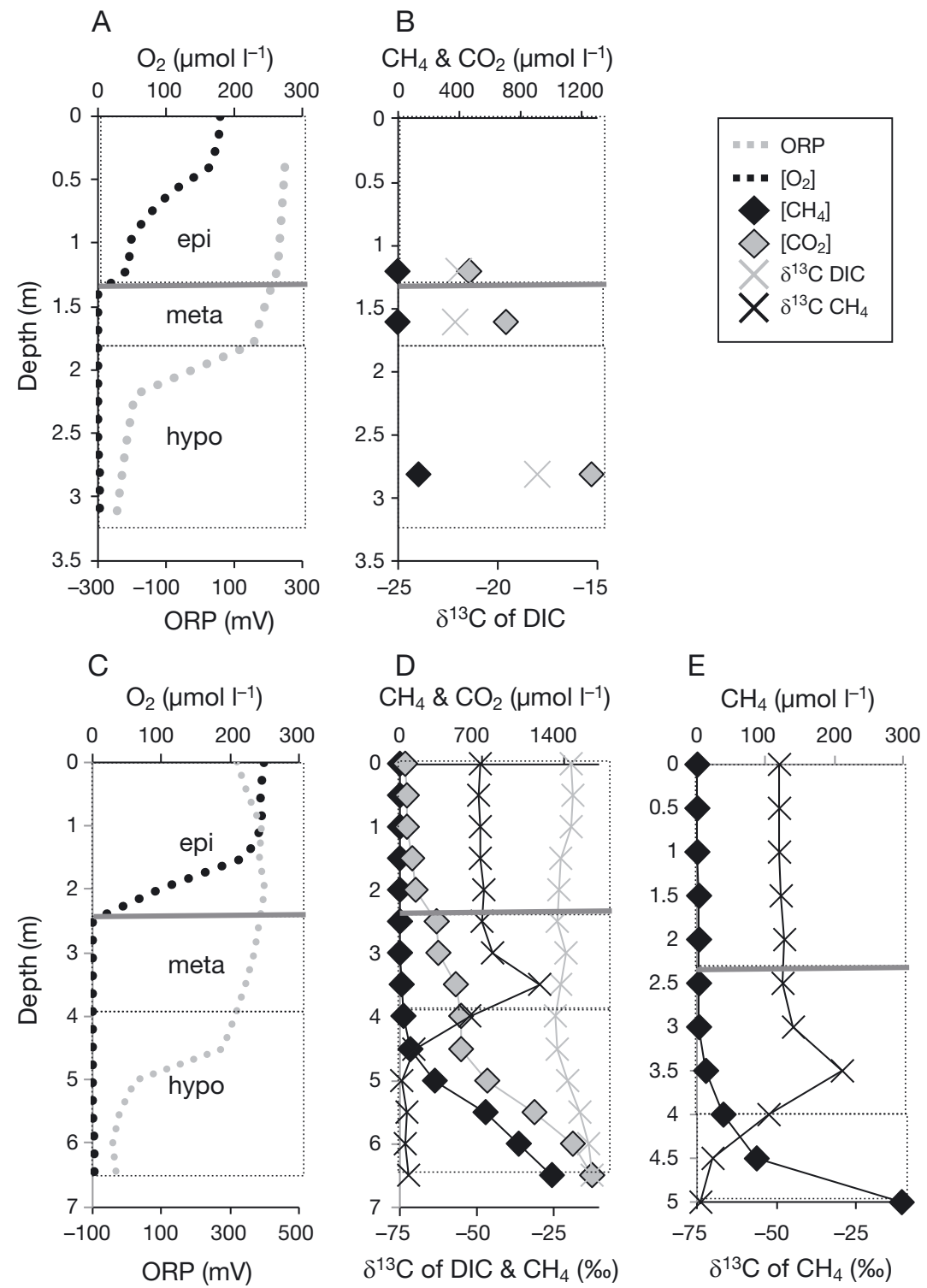

Fig. 1. Vertical depth profiles measured in 2 boreal lakes in Finland: (A) oxidation-reduction potential (ORP) and $\mathrm{O}_{2}$ concentration in Lake Mekkojärvi; (B) $\delta^{13} \mathrm{C}$ of dissolved inorganic carbon (DIC), and concentrations of $\mathrm{CH}_{4}$ and $\mathrm{CO}_{2}$ in Lake Mekkojärvi; (C) ORP and $\mathrm{O}_{2}$ concentration in Lake AlinenMustajärvi; (D) $\delta^{13} \mathrm{C}$ of DIC and $\mathrm{CH}_{4}$, and $\mathrm{CH}_{4}$ and $\mathrm{CO}_{2}$ concentrations in Lake Alinen-Mustajärvi; (E) $\delta^{13} \mathrm{C}$ and concentration of $\mathrm{CH}_{4}$ at a higher resolution for the $0-5 \mathrm{~m}$ layer in Lake Alinen-Mustajärvi. Oxycline depth is denoted with a grey line. The epi- (above the oxycline) as well as meta- and hypolimnion (below the oxycline) zones are indicated with dashed line boxes 


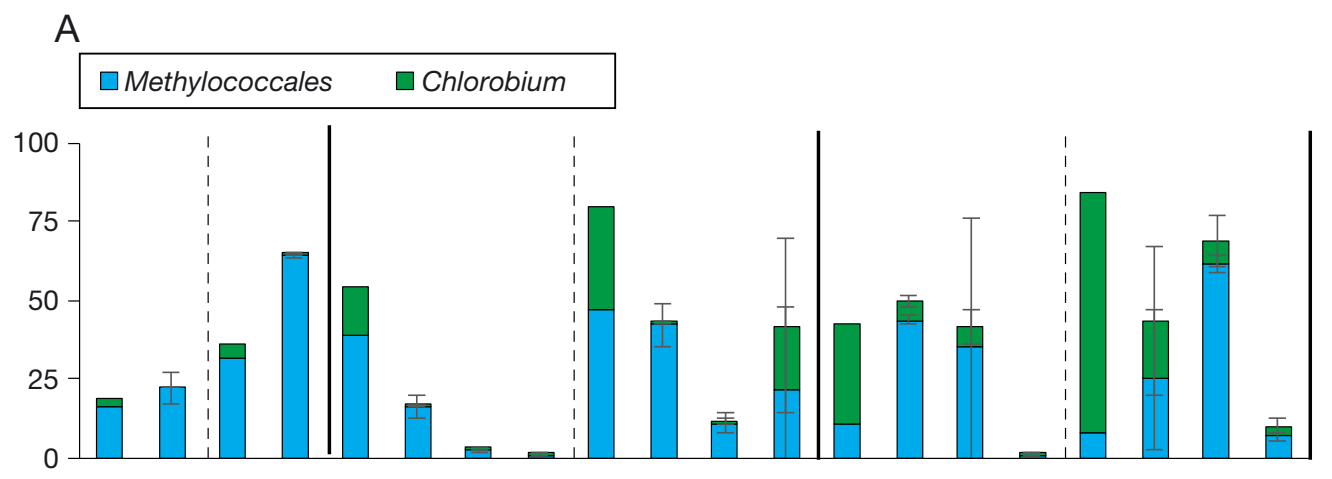

B
$\square$ OTU 3 (Methylobacter) 目 OTU 63 (Methylomonas)
国 OTU 27 (Methylobacter) ஐ OTU 67 (Methylomonas) 回 OTU 56 (CABC2E06) 凹 OTU 86 (CABC2E06)

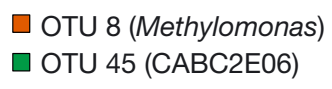

$\square$ OTU 8 (Methylomonas) 口 OTU 45 (CABC2E06)

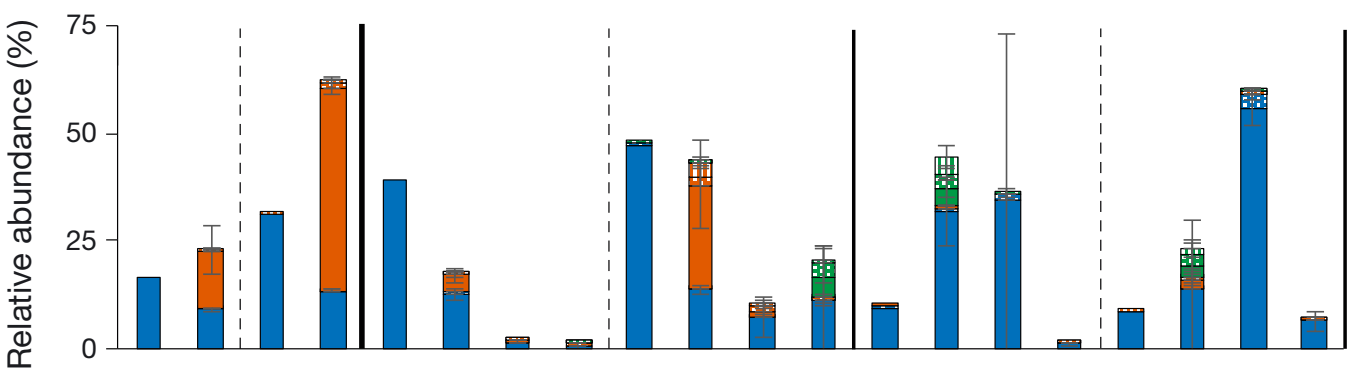

C

\begin{tabular}{|c|c|c|}
\hline$\square$ OTU 1 (Methylobacter) & $\boxminus$ OTU 6 (Methylomonas) & 四 OTU 5 (Methylomonas) \\
\hline W OTU 7 (Methylobacter) & 国 OTU 2 (Methylobacter) & $\square$ OTU 8 (Methylovulum) \\
\hline
\end{tabular}

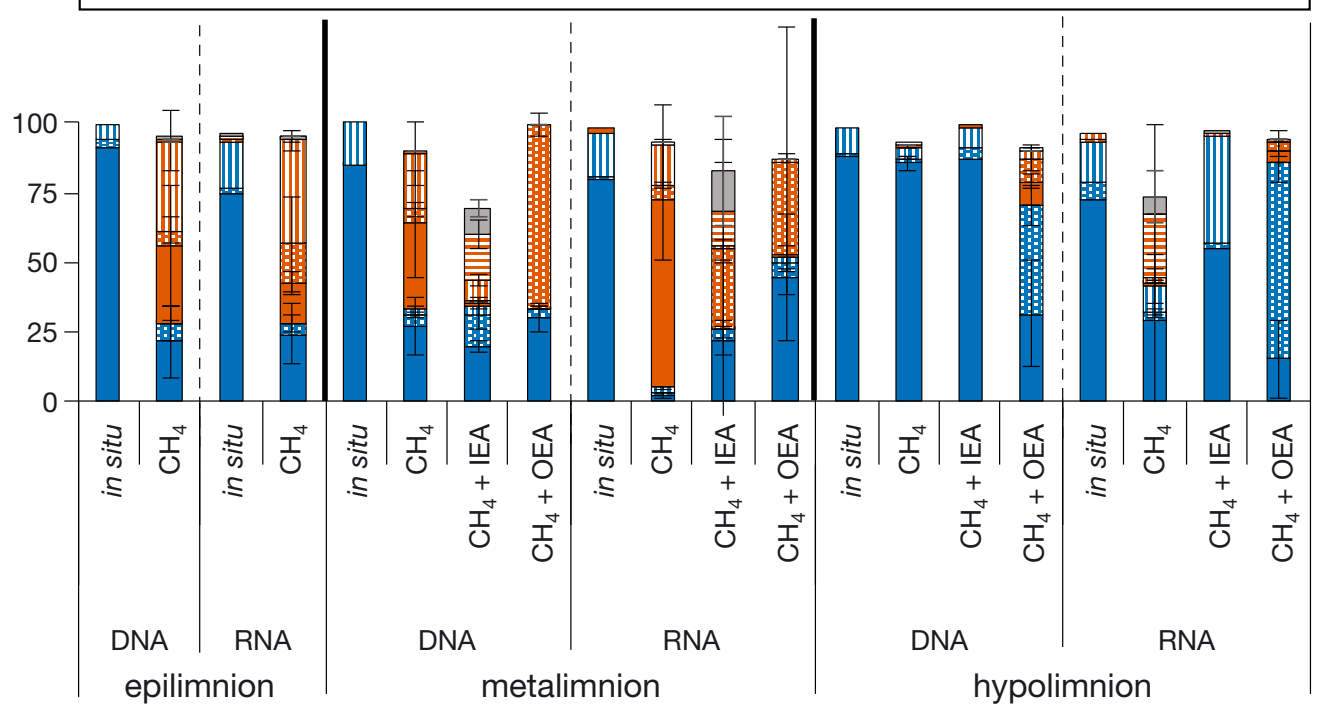

Fig. 2. Relative abundances of components of the microbial community in Lake Mekkojärvi, Finland: (A) Methylococcales and anoxygenic phototrophic $\mathrm{H}_{2} \mathrm{~S}$ and $\mathrm{Fe}^{2+}$-oxidizing (Chlorobium) bacteria; (B) dominant OTUs of Methylococcales (and their affiliation) based on the 16S rRNA gene and 16S rRNA $(C)$ dominant OTUs of Methylococcales based on the pmoA gene and mRNA transcripts. Values are shown for samples collected in situ and after experimental incubation (21 d) of water samples collected from the epi-, meta-, and hypolimnion and amended with ${ }^{13} \mathrm{C}_{-} \mathrm{CH}_{4},{ }^{13} \mathrm{C}_{-} \mathrm{CH}_{4}$ plus a mixture of inorganic electron acceptors (IEA: $\mathrm{NO}_{3}{ }^{-}, \mathrm{SO}_{4}{ }^{2-}, \mathrm{Fe}^{3+}$ and $\mathrm{Mn}^{4+}$ ), and ${ }^{13} \mathrm{C}_{-} \mathrm{CH}_{4}$ plus an organic EA (OEA: di-sodium anthraquinone-2, 6-disulfonate). 
A

B

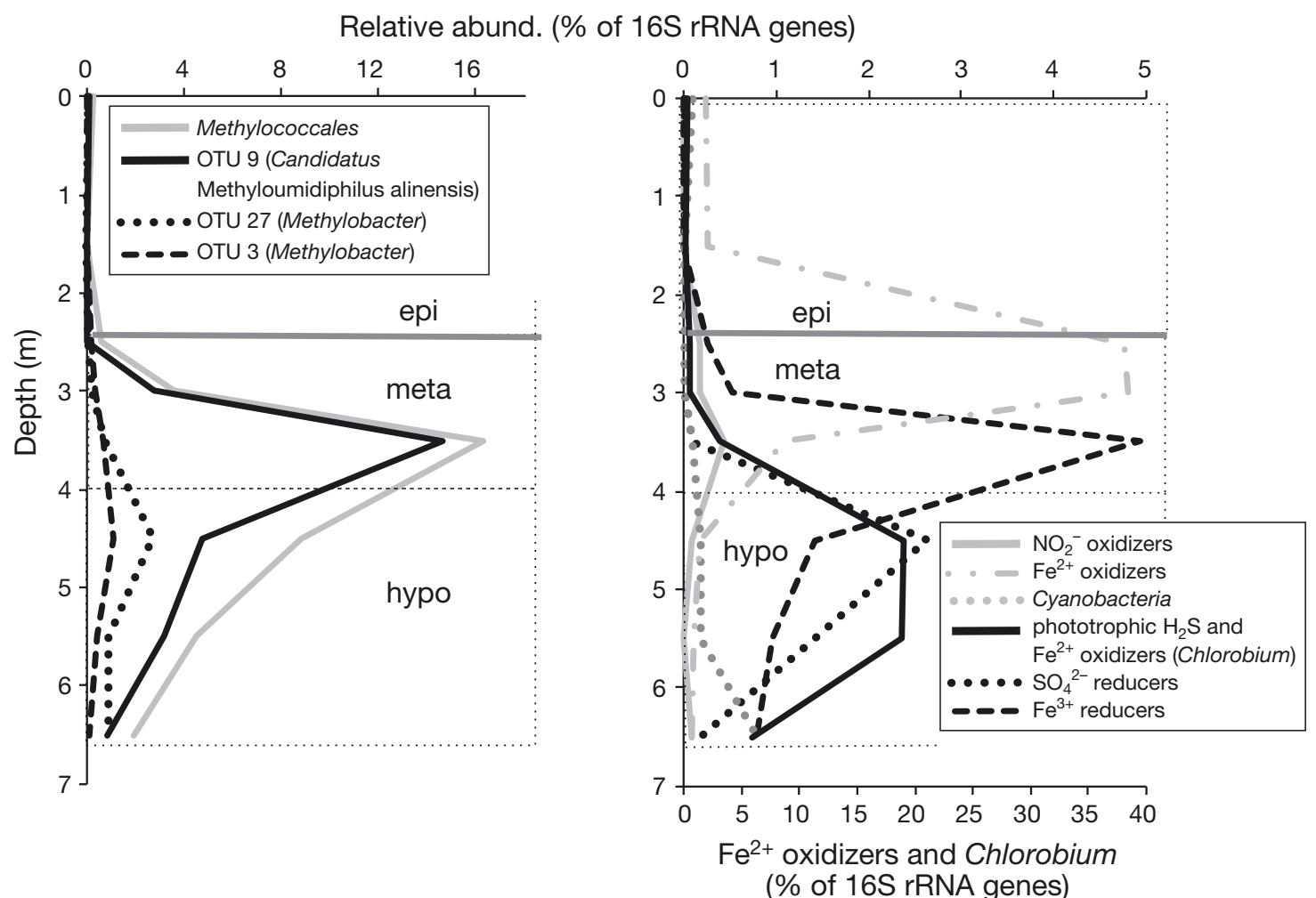

Fig. 3. Vertical depth profiles of relative abundances, measured as \% of 16S rRNA gene amplicons, of components of the microbial community in Lake Alinen-Mustajärvi, Finland: (A) total Methylococcales, and 3 dominant Methylococcales OTUs (and their taxonomic affiliation); (B) Cyanobacteria, aerobic $\mathrm{NO}_{2}{ }^{-}$and $\mathrm{Fe}^{2+}$-oxidizing bacteria, anaerobic $\mathrm{Fe}^{3+}$ and $\mathrm{SO}_{4}{ }^{2-}$ reducing bacteria as well as anoxygenic phototrophic $\mathrm{H}_{2} \mathrm{~S}$ and $\mathrm{Fe}^{2+}$-oxidizing bacteria. Oxycline depth is denoted with a grey line. Epi- (above the oxycline) as well as the meta- and hypolimnion (below the oxycline) zones are indicated with dashed line boxes. Note the different $x$-axes for $\mathrm{Fe}^{2+}$ oxidizers and Chlorobium in (B)

\section{Microbes in the study lakes analysed by DNA- and RNA-based amplicon sequencing}

The sample storage and nucleic acid extraction methods differed between lakes (see 'Materials and methods'). Therefore, detailed comparisons of relative abundances of microbial groups between the study lakes were not made. The methanotrophic bacterial community was dominated by gammaproteobacterial MOB of the order Methylococcales (i.e. MOB Type I) (Figs. 2 \& 3A). Alphaproteobacterial MOBs (i.e. MOB Type II) were very rare in Mekkojärvi $(<0.3 \%$ of bacteria in situ and $<1.7 \%$ of bacteria in incubated samples) and absent in Alinen-Mustajärvi amplicon libraries. Verrucomicrobial MOBs or putative anaerobic $\mathrm{CH}_{4}$-oxidizing bacteria belonging to phylum NC10 were not detected. Detailed phylogenetic analyses showed that the in situ Methylococcales community in Mekkojärvi was dominated by Methylobacter, i.e. 16S rRNA gene OTU 3 and pmoA OTU 1 (Figs. 2B,C, 4 \& 5). In contrast, in Alinen-Mustajärvi, a putative novel Methylococcales group, represented by $16 \mathrm{~S}$
rRNA gene OTU 9, substantially outnumbered the 2 other most abundant Methylobacter OTUs, OTUs 3 and 27 (Figs. 3A \& 4). OTU 9 was very rare in Mekkojärvi $(<0.1 \%$ in hypolimnion). To increase the confidence in the phylogenetic assignment of the dominant OTUs, the phylogenetic analyses of 16S rRNA genes were also performed using longer clone library sequences, which were previously collected from the study lakes, and contained more information than the shorter amplicon sequences (Figs. S3 \& S4). The analysis of AM949373 (469 bp) and HE616477 (828 bp) that shared $99 \%$ and $100 \%$ similarity with representative sequences of OTUs 3 and 27, respectively, gave further confirmation that these OTUs represented Methylobacter, as they had $98 \%$ similarity with their closest database representative, which was Methylobacter psychrophilus (Figs. 4, S3 \& S4). In addition, a representative sequence of OTU 9 and a highly similar $(99.7 \%$ similarity) clone library sequence, HE616416 (830 bp), previously collected from the water column of Alinen-Mustajärvi, were identically positioned in the phylogenetic tree, being $93.1 \%$ and 
Fig. 4. Phylogenetic tree of the 16S rRNA gene sequences of Methylococcales (i.e. Type I methane oxidizing bacteria [MOB]), showing the phylogenetic positions of representative sequences of most abundant OTUs from Lakes Alinen-Mustajärvi and Mekkojärvi, Finland. The tree was constructed using the maximum-likelihood algorithm with the GTR model. The length of the nucleotide sequences varies from 266 to $294 \mathrm{bp}$. Trees with longer clone library sequences collected previously, validating the phylogenetic position of OTUs 3, 9, and 27, are presented in Figs. S3 \& S4 in Supplement 2. The sequence from alphaproteobacterial methanotrophic bacteria (i.e. type II MOB) was used to root the tree. The scale bar indicates the number of substitutions per site. The numbers at the nodes indicate the percentage of occurrence in 100 bootstrapped trees (bootstrap values $>50 \%$ are shown)

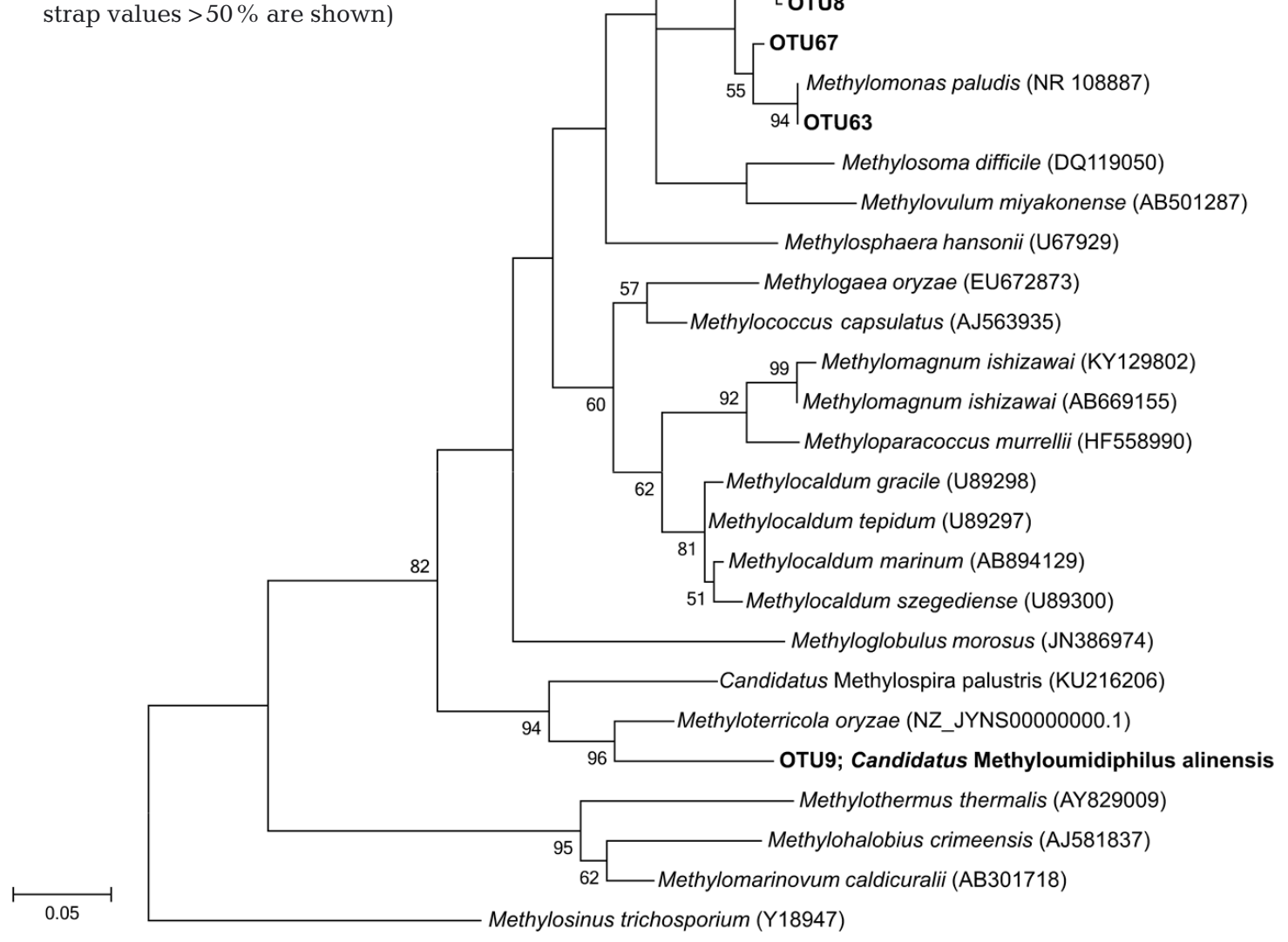

$89.9 \%$ similar, respectively, to the closest known Methylococcales genus, Methyloterricola (Figs. 4 \& S4). Since these similarities were less than the widely used $95 \%$ similarity threshold for classification of sequences into different genera, this group very likely belonged to a novel genus. Since OTU 9 representative sequence and the clone library sequence HE616416 shared 93\% and 90\% similarity, respectively, with the closest environmental database sequences from wet environments, i.e. wetland, lake sediment, rice rhizosphere, and subsurface geothermal water (data not shown), OTU 9 was given the following candidate names for genus and species: Candidatus Methyloumidiphilus alinensis. Methylo denotes potential consumption of methyl-compounds, umidi (from Latin umida, which means 'wet'), and philus (from Greek philos, which means 'friend, loving') denotes the preference for wet environments. Thus, Methyloumidiphilus is a methyl-using bacterium that prefers wet environments, and the species 


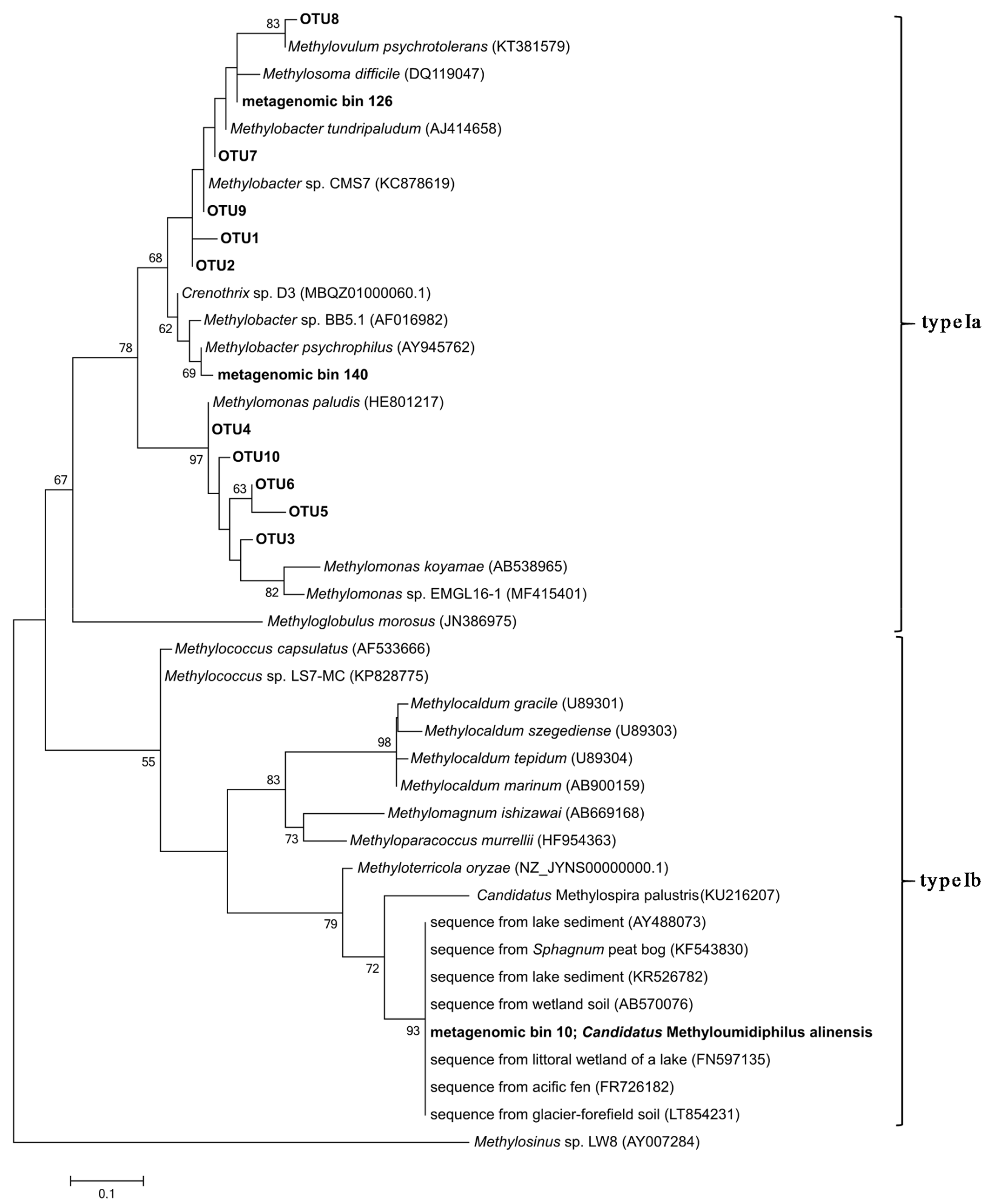

Fig. 5. Phylogenetic tree of deduced amino acid sequences of the pmoA gene of Methylococcales (i.e. Type I MOB divided into clusters Ia and Ib), showing the phylogenetic positions of representative sequences of most abundant OTUs from Lake Mekkojärvi as well as sequences from metagenomic bins from Lake Alinen-Mustajärvi. The tree was constructed using the maximum-likelihood algorithm with the JTT substitution model. The length of amino acid sequences is 75 . A tree with longer sequences validating the phylogenetic position of metagenomic bins 10 and 140 is presented in Fig. S9 in Supplement 2. The sequence from alphaproteobacterial methanotrophic bacteria (i.e. Type II MOB) was used to root the tree. The scale bar indicates the number of substitutions per site. The numbers at the nodes indicate the percentage of occurrence in 100 bootstrapped trees (bootstrap values $>50 \%$ are shown) 

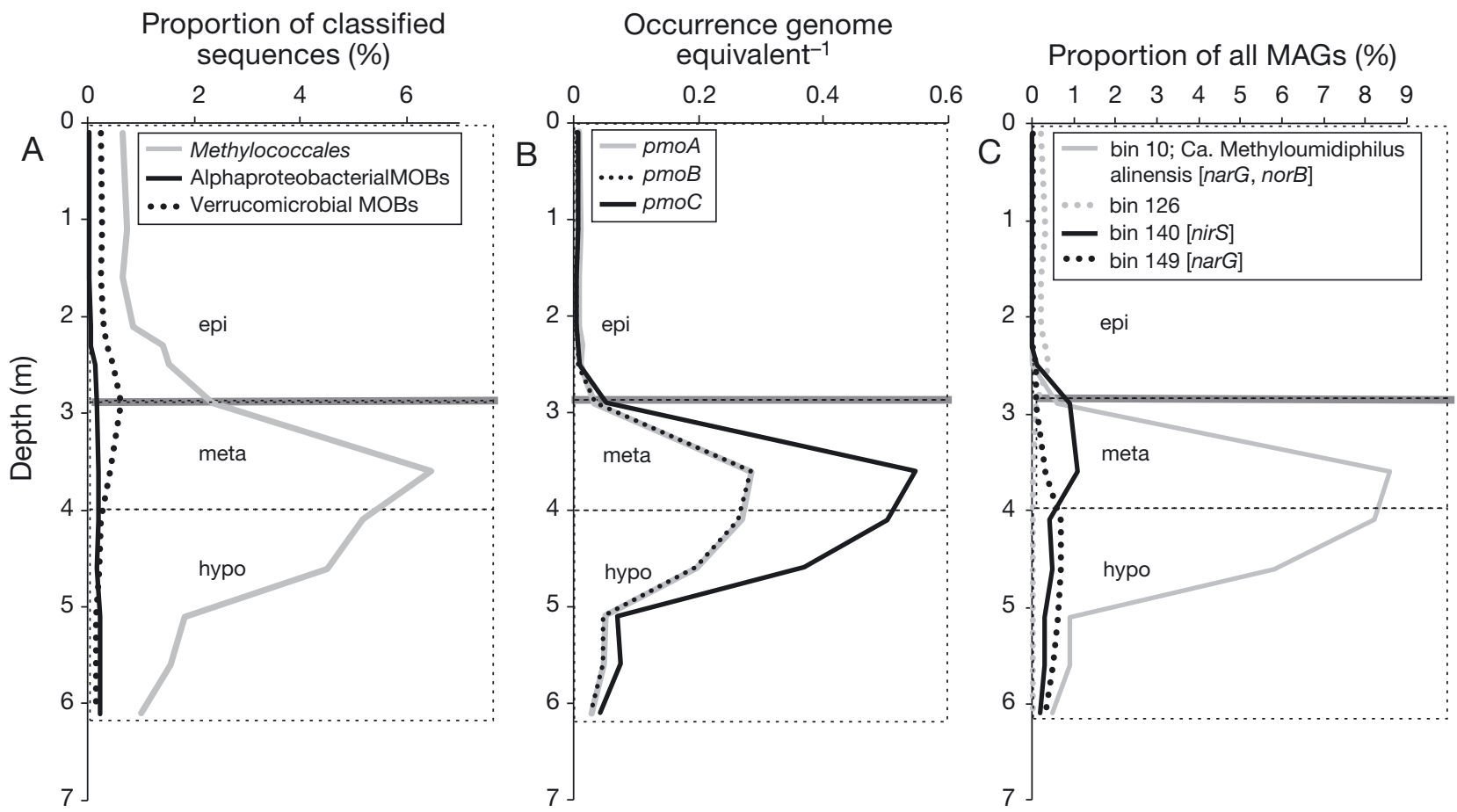

Fig. 6. Vertical depth profiles from Lake Alinen-Mustajärvi, Finland based on shotgun metagenomic analysis for (A) different groups of aerobic methanotrophic bacteria (MOB); (B) genes coding for particulate methane monooxygenase Subunits a $(p m o A), \mathrm{b}(p m o B)$, and c (pmoC); (C) metagenome assembled genomes (MAGs; i.e. metagenomic bins) of Methylococcales. The denitrification genes found within the MAGs are denoted in brackets after the name of each bin in (C). Oxycline depth is denoted with a grey line. The epi- (above the oxycline) as well as meta- and hypolimnion (below the oxycline) zones are indicated with dashed line boxes

name alinensis denotes the lake in which it was first detected, Lake Alinen-Mustajärvi.

MOBs were present both above and below the oxycline, down to the deepest sampling depths in both lakes. Based on the results from Mekkojärvi, they were also actively transcribing pmoA (Fig. 2C). In Mekkojärvi, the in situ relative abundance of MOBs was highest in the metalimnion and lowest in the hypolimnion, based on both the 16S rRNA and 16S rRNA gene sequences. The relative abundance of putative anoxygenic phototrophic $\mathrm{H}_{2} \mathrm{~S}$ and $\mathrm{Fe}^{2+}$ oxidizing Chlorobium increased from the epilimnion to the hypolimnion (Fig. 2A). Cyanobacteria were present below the oxycline in the meta- and hypolimnion but with low relative abundance $(<0.3 \%$ of 16S rRNA sequences) (data not shown).

The higher depth resolution sampling in AlinenMustajärvi revealed the total Methylococcales and Ca. M. alinensis maximum to be below the oxycline, at $3.5 \mathrm{~m}$ in the metalimnion, which corresponded to depths where $\mathrm{CH}_{4}$ concentration increased towards the bottom, $\mathrm{CO}_{2}$ concentration was stable, and $\delta^{13} \mathrm{C}$ of $\mathrm{CH}_{4}$ and DIC reached their maximum and minimum, respectively (Figs. 1D,E \& 3A). The putative anaerobic $\mathrm{Fe}^{3+}$-reducing bacteria (mainly Geothrix) and aerobic $\mathrm{NO}_{2}{ }^{-}$-oxidizing bacteria (mostly Candidatus Nitrotoga) peaked at the same depth (Fig. 3B). The 2 most abundant Methylobacter-OTUs peaked lower in the water column than $C a$. M. alinensis, at the same depth $(4.5 \mathrm{~m})$ as the putative $\mathrm{SO}_{4}{ }^{2-}$-reducing (mostly Desulfovibrio and Desulfobulbaceae) and anoxygenic phototrophic $\mathrm{H}_{2} \mathrm{~S}$, and $\mathrm{Fe}^{3+}$-oxidizing bacteria (Chlorobium) (Fig. 3). Putative aerobic $\mathrm{Fe}^{2+}$ oxidizing bacteria (mainly Ferrovum) were generally more numerous higher in the water column than any other studied group (Fig. 3). Cyanobacteria were present in the meta- and hypolimnion but with low relative abundance $(<0.8 \%$ of $16 \mathrm{~S}$ rRNA gene sequences).

The final mcrA dataset consisted only of methanogenic archaea, which were present both above and below the oxycline in both lakes, and were actively transcribing mcrA in each study layer of Mekkojärvi (Figs. S5 \& S6). However, in the raw data preceding singleton-removal and subsampling, ANME archaea belonging to ANME 2D had a marginal abundance (maximum $0.3 \%$ of $\mathrm{mcr} A$ sequences) in some incubated metalimnion and hypolimnion samples of Mekkojärvi. Yet, they neither transcribed mcrA in any of the samples nor were present in situ in the study lakes. 


\section{Methanotrophs in Lake Alinen-Mustajärvi studied by shotgun metagenomic analysis}

The oxycline was located slightly deeper $(2.9 \mathrm{~m})$, when the sampling for the metagenomic analyses were conducted (i.e. $2 \mathrm{wk}$ after sampling for other analyses) (Fig. S7A). The size of the metagenomic libraries varied from $\sim 5$ to $\sim 11 \mathrm{~Gb}$, and their coverage from $\sim 40$ to $\sim 75 \%$ (Fig. S7B). In accordance with $16 \mathrm{~S}$ rRNA and mcrA gene amplicon results, anaerobic methanotrophs were not detected, and Methylococcales were the dominant MOB group, having the highest relative abundance below the oxycline in the metalimnion (Fig. 6A). Alphaproteobacterial and verrucomicrobial MOBs were also detected in AlinenMustajärvi, but they were rare (Fig. 6A). Vertical variation in the abundances of $p m o A$, as well as genes coding for particulate methane monooxygenase Subunits b $(p m o B)$ and $\mathrm{c}(p m o C)$, followed that of Methylococcales (Fig. 6B).

From a total of 8 MAGs affiliated to MOBs, 4 were of high quality, i.e. Bins 10 (95.3\% complete, $4.8 \%$ contaminated), $126(95.8 \%, 0.7 \%), 140(66.7 \%, 0 \%)$, and $149(94.1 \%, 1.4 \%)$ and will be considered further (Fig. S8); they all belonged to Methylococcales. Three of them had their highest relative abundance below the oxycline, Bins 10 and 140 in the metalimnion and Bin 149 in the hypolimnion, while Bin 126 had its highest abundance in the epilimnion (Fig. 6C). The 16S rRNA gene sequences of the bins were not obtained. However, PhyloPhlAn, which uses whole-genome sequence data, placed the most dominant bin, Bin 10, closest to Methyloterricola oryzae (Fig. S8), which is in accordance with the phylogenetic position of the most dominant Methylococcales-OTU, OTU 9 (Figs. 4 \& S4). Furthermore, the deduced amino acid sequence of pmoA of Bin 10 was most similar to Methyloterricola (Figs. 5 \& S9). Altogether, this suggests that Bin 10 and the 16S rRNA gene OTU 9 represent the same species. However, in accordance with the 16S rRNA gene results, the deduced amino acid sequence of pmoA of Bin 10 was still quite distantly related to $M$. oryzae, sharing only $90 \%$ similarity (Figs. 5 \& S9). This confirms that OTU 9 and metagenomic Bin 10 represent a novel genus and species of Methylococcales. The deduced amino acid pmoA sequence of Bin 10 shared 97 to $100 \%$ similarity with the closest environmental database sequences, which were dominantly from wet environments (peatlands, wetlands, lake and river sediments) (Figs. 5 \& S9), which further supports our choice of name for this novel genus (see 'Microbes in the study lakes analysed by DNA- and RNA-based
Table 2. Potential $\mathrm{CH}_{4}$ oxidation rates, measured as excess ${ }^{13} \mathrm{C}$-dissolved inorganic carbon (DIC) production during incubation $(21 \mathrm{~d})$ of water samples collected from the epi-, meta-, and hypolimnion of Lake Mekkojärvi, Finland, and subjected to different treatments. Minimum and maximum values of exceess ${ }^{13} \mathrm{C}$-DIC production are shown $(\mathrm{n}=2$ replicates per treatment). Inorganic electron acceptors (EA) included a mixture of $\mathrm{NO}_{3}{ }^{-}, \mathrm{SO}_{4}{ }^{2-}, \mathrm{Fe}^{3+}$, and $\mathrm{Mn}^{4+}$; while disodium anthraquinone-2,6-disulfonate was used as an organic EA

\begin{tabular}{|lll|}
\hline Depth zone & Treatment & $\begin{array}{l}\text { Excess }{ }^{13} \mathrm{C}-\mathrm{DIC} \\
\text { production }(\min ; \mathrm{max}) \\
\left(\mathrm{nmol}^{-1} \mathrm{~d}^{-1} \text { ) }\right.\end{array}$ \\
\hline Epilimnion & $\mathrm{CH}_{4}$ & $479.5 ; 916.5$ \\
Metalimnion & $\mathrm{CH}_{4}$ & $977.4 ; 1140.7$ \\
& $\mathrm{CH}_{4}+$ inorg EAs & $132.0 ; 156.6$ \\
& $\mathrm{CH}_{4}+$ org. EAs & $59.0 ; 134.6$ \\
Hypolimnion & $\mathrm{CH}_{4}$ & $1093.4 ; 1147.5$ \\
& $\mathrm{CH}_{4}+$ inorg. EAs & $691.9 ; 839.5$ \\
& $\mathrm{CH}_{4}+$ org. EAs & $33.2 ; 34.2$ \\
\hline
\end{tabular}

amplicon sequencing' above). In contrast to Bin 10, PhyloPhlAn placed the other Methylococcales bins closest to Crenothrix but to a branch without any genomes from isolated organisms (Fig. S8). However, although we could not recover a $p m o A$ gene for Bin 149, the analysis of pmoA genes of Bins 126 and 140 suggested them to be most closely related to Methylobacter (Figs. 5 \& S9). Although it is possible that Crenothrix can obtain their pmoA gene via lateral gene transfer from other Methylococcales (Oswald et al. 2017), neither of the $16 \mathrm{~S}$ rRNA gene OTUs in Alinen-Mustajärvi were affiliated with Crenothrix (Figs. 4, S3, \& S4). Hence, it is likely that Bins 126, 140 , and 149 represented species that have no genomes or isolated members available (e.g. Methylobacter psychrophilus). Due to this uncertainty, these bins were not assigned to genera. Interestingly, the bins that thrived below the oxycline (i.e. Bins 10, 140, and 149) contained genes coding for denitrification enzymes, i.e. narG (nitrate reductase) in Bins 10 and 149, nirS (nitrite reductase) in Bin 140, and norB (nitric oxide reductase) in Bin 10, while the genetic denitrification potential was not detected in Bin 126 that was most abundant in the epilimnion (Fig. 6C).

\section{Variation in potential $\mathrm{CH}_{4}$ oxidation and in microbial community structure in the incubation experiments}

In Mekkojärvi, potential $\mathrm{CH}_{4}$ oxidation based on the accumulation of excess ${ }^{13} \mathrm{C}$-DIC in incubations 

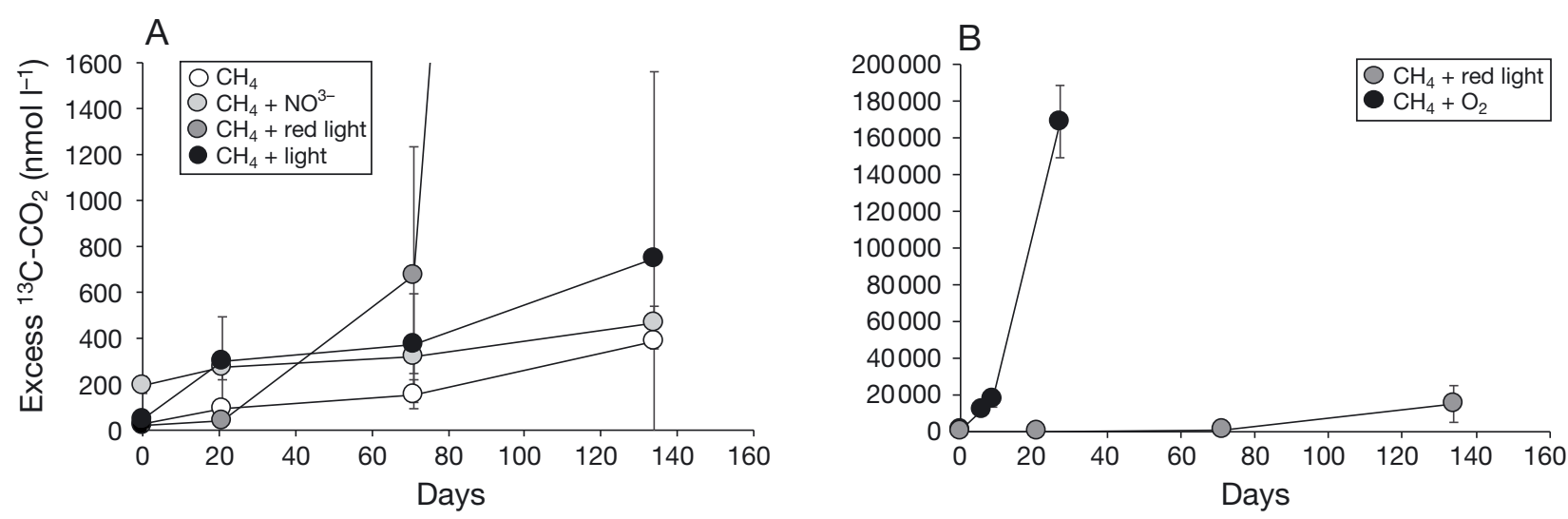

Fig. 7. Accumulation of excess ${ }^{13} \mathrm{C}-\mathrm{CO}_{2}$ during incubation of concentrated water samples (average $\pm \mathrm{SD}, \mathrm{n}=5$ ) collected from the hypolimnion $\left(5.5 \mathrm{~m}\right.$ ) of Lake Alinen-Mustajärvi and subjected to different treatments: (A) $\mathrm{CH}_{4}$ and $\mathrm{CH}_{4}+\mathrm{NO}_{3}{ }^{-}$in the dark, and $\mathrm{CH}_{4}$ under red and normal light; (B) $\mathrm{CH}_{4}+\mathrm{O}_{2}$ in the dark, and $\mathrm{CH}_{4}$ under red light. Note the significant accumulation of ${ }^{13} \mathrm{C}-\mathrm{CO}_{2}$ during the period $71-134 \mathrm{~d}$ in the red light treatment

was generally higher in the meta- and hypolimnion than in the epilimnion (Table 2). The addition of inorganic and organic EAs decreased the potential $\mathrm{CH}_{4}$ oxidation (Table 2). However, the decrease was considerably lower $(32 \%)$ in the treatment with inorganic EAs in the hypolimnion than in the other treatments (86 to $97 \%$ ) (Table 2).

The microbial community variations between the treatments were studied by amplicon sequencing in Mekkojärvi experiments. Besides the Methylococcales OTUs that dominated in situ (i.e. 16S rRNA OTU 3 and pmoA OTU 1), there were also other OTUs that were increasingly present after the experimental incubations in Mekkojärvi (Fig. 2B,C). However, in this study, we focused specifically on the effects of EAs on the MOB OTUs that dominated in situ as well as on total Methylococcales. EA-amended samples generally had fewer Methylococcales than the $\mathrm{CH}_{4}$ treatment, except for the inorganic EA-induced increase at the level of 16S rRNA in the hypolimnion (Fig. 2A). Organic EAs in general decreased the relative abundance of Methylococcales OTU 3 when compared to the $\mathrm{CH}_{4}$ treatment (Fig. 2B). In contrast, inorganic EAs increased the relative abundance of OTU 3 in the hypolimnion but slightly decreased it in the metalimnion at the level of 16S rRNA (Fig. 2B). In addition, there was no inorganic EA-driven change in OTU 3 abundance in the hypolimnion but a decrease in metalimnion at the 16S rRNA gene level (Fig. 2B). Compared to the $\mathrm{CH}_{4}$ treatment, organic EAs decreased the relative abundance of Methylobacter OTU 1 at the level of both the pmoA gene and its mRNA transcripts in the hypolimnion, whereas they did not affect it at the level of pmoA gene, but even increased it at the level of mRNA transcripts in the metalimnion (Fig. 2C). In contrast, inorganic EAs increased the rel-
Table 3. Potential $\mathrm{CH}_{4}$ oxidation rates, measured using an isotope ratio mass spectrometer (IRMS) as average $( \pm \mathrm{SD})$ excess ${ }^{13} \mathrm{C}-\mathrm{CO}_{2}$ production at different time periods during incubations of concentrated water samples collected from the hypolimnion (depth $5.5 \mathrm{~m}$ ) of Lake Alinen-Mustajärvi, Finland, and subjected to different treatments $(\mathrm{n}=5$ replicates per treatment). Potential $\mathrm{CH}_{4}$ oxidation could not be assessed for samples amended with humic acids $\left(\mathrm{CH}_{4}+\mathrm{hu}-\right.$ mic acids and $\mathrm{CH}_{4}$ + humic acids $+\mathrm{Fe}^{3+}$ ) due to $\mathrm{CO}_{2}$ concentrations being below the detection limit of the IRMS. Different letters in the final column indicate significant differences in $\mathrm{CH}_{4}$ oxidation between treatments (1-way ANOVA, $\mathrm{p}<$ 0.05). $\mathrm{CH}_{4}$ oxidation rates in treatments with added $\mathrm{O}_{2}$ were many-fold higher than in other treatments and were therefore excluded from the statistical test

\begin{tabular}{|c|c|c|c|}
\hline $\begin{array}{l}\text { Time } \\
\text { period } \\
\text { (d) }\end{array}$ & Treatment & $\begin{array}{l}\text { Excess }{ }^{13} \mathrm{C}-\mathrm{CO}_{2} \\
\text { production } \\
\left(\mathrm{nmol} \mathrm{l}^{-} 1 \mathrm{~d}^{-1}\right)\end{array}$ & \\
\hline $0-21$ & $\begin{array}{l}\mathrm{CH}_{4} \\
\mathrm{CH}_{4}+\mathrm{NO}_{3}^{-} \\
\mathrm{CH}_{4} \text { in red light } \\
\mathrm{CH}_{4} \text { in light } \\
\mathrm{CH}_{4}+\mathrm{SO}_{4}{ }^{2-} \\
\mathrm{CH}_{4}+\mathrm{Fe}^{3+}\end{array}$ & $\begin{array}{l}3.2 \pm 0.3 \\
3.6 \pm 2.5 \\
1.1 \pm 0.3 \\
12.1 \pm 9.2 \\
0 \\
0\end{array}$ & $\begin{array}{l}\mathrm{a} \\
\mathrm{a} \\
\mathrm{a} \\
\mathrm{b}\end{array}$ \\
\hline $21-71$ & $\begin{array}{l}\mathrm{CH}_{4} \\
\mathrm{CH}_{4}+\mathrm{NO}_{3}^{-} \\
\mathrm{CH}_{4} \text { in red light } \\
\mathrm{CH}_{4} \text { in light } \\
\mathrm{CH}_{4}+\mathrm{SO}_{4}{ }^{2-} \\
\mathrm{CH}_{4}+\mathrm{Fe}^{3+}\end{array}$ & $\begin{array}{l}1.3 \pm 1.3 \\
0.9 \pm 1.5 \\
12.7 \pm 11.1 \\
2.2 \pm 3.8 \\
0 \\
0\end{array}$ & $\begin{array}{l}\mathrm{a} \\
\mathrm{a} \\
\mathrm{b} \\
\mathrm{a}\end{array}$ \\
\hline $71-134$ & $\begin{array}{l}\mathrm{CH}_{4} \\
\mathrm{CH}_{4}+\mathrm{NO}_{3}^{-} \\
\mathrm{CH}_{4} \text { in red light } \\
\mathrm{CH}_{4} \text { in light } \\
\mathrm{CH}_{4}+\mathrm{SO}_{4}^{2-} \\
\mathrm{CH}_{4}+\mathrm{Fe}^{3+}\end{array}$ & $\begin{array}{l}3.7 \pm 0.6 \\
2.3 \pm 1.2 \\
217.3 \pm 160.0 \\
6.6 \pm 12.5 \\
0 \\
0\end{array}$ & $\begin{array}{l}\mathrm{a} \\
\mathrm{a} \\
\mathrm{b} \\
\mathrm{a}\end{array}$ \\
\hline $\begin{array}{l}0-6 \\
6-9 \\
9-27\end{array}$ & $\begin{array}{l}\mathrm{CH}_{4}+\mathrm{O}_{2} \\
\mathrm{CH}_{4}+\mathrm{O}_{2} \\
\mathrm{CH}_{4}+\mathrm{O}_{2}\end{array}$ & $\begin{array}{l}1714.6 \pm 354.0 \\
2145.1 \pm 1446.3 \\
8391.7 \pm 1092.8\end{array}$ & \\
\hline
\end{tabular}


ative abundance of OTU 1 at the level of pmoA transcripts, whereas they did not generally affect it at the level of pmoA genes (Fig. 2C).

Based on the accumulation of excess ${ }^{13} \mathrm{C}$-DIC, potential $\mathrm{CH}_{4}$ oxidation took place during the $6.5 \mathrm{mo}$ pre-incubation of the hypolimnion samples $(5.5 \mathrm{~m}$ depth) of Alinen-Mustajärvi (Fig. S10). Concurrent accumulation of sulfide and $\mathrm{CH}_{4}$ indicated that anaerobic conditions prevailed during this period (Fig. S10). Despite the long pre-incubation, it was confirmed by $16 \mathrm{~S}$ rRNA gene amplicon sequencing that the same Methylococcales OTUs that dominated in situ (i.e. OTUs 3, 9 and 27) dominated the pre-incubation bottle 1 mo before the onset of the EA and light experiments (thus, after 5.5 mo pre-incubation). The relative abundance of Methylococcales was slightly lower in the pre-incubation bottle (3.7\%) than in situ $(4.5 \%)$, but these numbers are not directly comparable due to the different sample storage and DNA extraction methods. Compared to the treatment with only $\mathrm{CH}_{4}$, the amendment of $\mathrm{O}_{2}$ substantially increased the potential $\mathrm{CH}_{4}$ oxidation (based on the accumulation of excess ${ }^{13} \mathrm{C}-\mathrm{CO}_{2}$ ) (Fig. 7, Table 3). In addition, normal light enhanced potential $\mathrm{CH}_{4}$ oxidation during the first $21 \mathrm{~d}$, while red light increased it during the later stages of incubation (Fig. 7, Table 3). In contrast, the potential $\mathrm{CH}_{4}$ oxidation rate was not affected by $\mathrm{NO}_{3}{ }^{-}$and was significantly decreased (i.e. not observed to take place at all) in samples amended with $\mathrm{Fe}^{3+}$ or $\mathrm{SO}_{4}{ }^{2-}$ (Table 3). However, despite similar $\mathrm{CH}_{4}$ oxidation rates, the addition of $\mathrm{NO}_{3}{ }^{-}$generally led to a higher concentration of excess ${ }^{13} \mathrm{C}_{-}-\mathrm{CO}_{2}$ than the addition of $\mathrm{CH}_{4}$ alone (Fig. 7). $\mathrm{CH}_{4}$ oxidation could not be assessed for samples amended with humic acids due to the $\mathrm{CO}_{2}$ concentration being below the detection limit of IRMS.

\section{DISCUSSION}

In this study, we demonstrated active $\mathrm{CH}_{4}$ oxidation below the oxic-anoxic interface in 2 boreal humic oxygen-stratified lakes, supporting previous findings about these environments (Kankaala et al. 2006, Peura et al. 2012, Nykänen et al. 2014). Incubations without EA amendments led to slightly higher $\mathrm{CH}_{4}$ oxidation potential in water samples collected from below rather than above the oxycline in Mekkojärvi (Table 2). MOBs also actively transcribed $p m o A$ at all depth layers in Mekkojärvi (Fig. 2C). In addition, as microbial $\mathrm{CH}_{4}$ oxidation fractionates against the heavier isotope, enriching the residual $\mathrm{CH}_{4}$ in ${ }^{13} \mathrm{C}$ (Whiticar 1999), the concurrent upward decrease in
$\mathrm{CH}_{4}$ concentration and increase in its $\delta^{13} \mathrm{C}$ in the 5 to $3.5 \mathrm{~m}$ layer confirms previous findings that in situ $\mathrm{CH}_{4}$ oxidation was most active below the oxycline in Alinen-Mustajärvi (Fig. 1E) (Peura et al. 2012). As oxidation of $\mathrm{CH}_{4}$ produces $\mathrm{CO}_{2}$ with a lower $\delta^{13} \mathrm{C}$ value than oxidation of organic matter, the lowest $\delta^{13} \mathrm{C}$ of DIC observed at the same depth layers further support active $\mathrm{CH}_{4}$ oxidation (Fig. 1D).

As hypothesized, the presence of Methylococcales and the lack of NC10 bacteria in the bacterial 16S rRNA data, as well as the lack of ANME archaea in the mcrA data, indicate that aerobic MOBs were the dominant methanotrophs below the oxycline in these boreal lakes, in accordance with evidence from temperate lakes (Blees et al. 2014, Milucka et al. 2015, Oswald et al. 2015, 2016a,b). However, it has to be acknowledged that the PCR amplicon sequencing approach, despite adequately resolving the sequence diversity in the amplicon pool, suffers from PCR-associated problems (e.g. primer bias and amplicon length), which can affect the view on microbial diversity (Hong et al. 2009, Engelbrektson et al. 2010). Therefore, we used PCR-free shotgun metagenomic analysis to confirm our findings by showing exclusive dominance of MOBs, mainly Methylococcales, in the methanotrophic community in Alinen-Mustajärvi. The general lack of EA-induced $\mathrm{CH}_{4}$ oxidation in anaerobic incubations gave further support for the lack of activity of the typical AOM organisms (i.e. ANME archaea and NC1O bacteria). In general, their activity seems to be limited to sediments in lakes (Deutzmann et al. 2014, á Norði \& Thamdrup 2014), which is probably due to lower environmental stability in water columns, which is less suitable for these slow-growing organisms.

PAR is known to be above the lowest threshold for oxygenic photosynthesis and chlorophyll a to be present below the oxycline in both study lakes during summer days (see 'Materials and methods'). Accordingly, this study found potentially photosynthetic Cyanobacteria below the oxycline in both study lakes. In addition, isotopic data indicated active $\mathrm{CH}_{4}$ oxidation in Alinen-Mustajärvi, and the relative abundance of MOBs was highest below the oxycline in both lakes (Figs. 1-3 \& 6). Together with the results on light-enhanced potential $\mathrm{CH}_{4}$ oxidation in the hypolimnion of Alinen-Mustajärvi (Table 3), this suggests that oxygenic photosynthesisdriven $\mathrm{CH}_{4}$ oxidation by MOBs is potentially responsible for a major part of $\mathrm{CH}_{4}$ consumption below the oxycline in shallow humic lakes of the boreal zone during summer days. This finding is in agreement with the previous results from temperate lakes and 
further confirms our hypothesis on MOBs dominating water column methanotrophic activity below the oxycline in oxygen-stratified lakes (Milucka et al. 2015, Oswald et al. 2015).

Interestingly, the relative abundance of MOBs in Alinen-Mustajärvi peaked below the other major aerobic bacterial group, $\mathrm{Fe}^{2+}$-oxidizing bacteria, at the same depth layers as anaerobic bacteria (Fig. 3), in accordance with results from temperate Lake Rotsee, Switzerland (Oswald et al. 2015, Brand et al. 2016). This depth distribution pattern was very likely due to the inhibitory effect of light on MOB activity, which can take place in PAR as low as $4 \mu \mathrm{mol}$ photons $\mathrm{m}^{-2} \mathrm{~s}^{-1}$ (Dumestre et al. 1999, Murase \& Sugimoto 2005). Indeed, the estimated PAR was below this limit (maximum $\sim 3.5 \mu \mathrm{mol}$ photons $\mathrm{m}^{-2} \mathrm{~s}^{-1}$ at $3.5 \mathrm{~m}$ depth) at the 5 to $3.5 \mathrm{~m}$ depth layer in AlinenMustajärvi, where $\mathrm{CH}_{4}$ oxidation and the relative abundance of MOBs was highest (Figs. 1D,E \& 3A). Furthermore, in Mekkojärvi, MOB relative abundance was lower in the epilimnion with higher PAR $\left(\sim 4.2 \mu \mathrm{mol}\right.$ photons $\left.\mathrm{m}^{-2} \mathrm{~s}^{-1}\right)$ than in the metalimnion ( 0.4 $\mu \mathrm{mol}$ photons $\mathrm{m}^{-2} \mathrm{~s}^{-1}$ ) (Fig. 2A). By oxidizing $\mathrm{CH}_{4}$ below the oxycline, MOBs also potentially supported the daytime metabolism of anaerobes by sustaining anoxic conditions via immediately consuming the $\mathrm{O}_{2}$ generated by the oxygenic photosynthesis.

Since AOM organisms were not present, the measured $\mathrm{CH}_{4}$ oxidation in the dark anaerobic treatments could be due to both MOB activity as well as trace methane oxidation by methanogens (Moran et al. 2005). The general EA-induced decreases in $\mathrm{CH}_{4}$ oxidation actually indicate a contribution of trace methane oxidation, since it is known to decrease concurrently with methanogenesis, when methanogenic samples are exposed to increased availability of EAs other than $\mathrm{CO}_{2}$ (Tables 2 \& 3) (Moran et al. 2005, Meulepas et al. 2010, Timmers et al. 2016). However, the concurrent transcription of pmoA of MOBs and mcrA of methanogens in Mekkojärvi experiments show that MOBs were also active in the dark and anaerobic incubations (Figs. 2C \& S5). Nonetheless, except for the $\mathrm{NO}_{3}{ }^{-}$treatment in Alinen-Mustajärvi experiments, EAs seemed to decrease the $\mathrm{CH}_{4}$ oxidation activity of MOBs, as suggested by the general EA-induced decreases in the relative abundance of Methylococcales (Fig. 2A). As $\mathrm{NO}_{3}{ }^{-}$addition would also be expected to decrease trace methane oxidation, the insignificant effect of $\mathrm{NO}_{3}{ }^{-}$on $\mathrm{CH}_{4}$ oxidation in Alinen-Mustajärvi experiments could actually stem from a simultaneous decrease in trace methane oxidation and an increase in MOB-driven methane oxidation (Table 3). The generally higher levels of excess ${ }^{13} \mathrm{C}-\mathrm{CO}_{2}$ in the $\mathrm{CH}_{4}+\mathrm{NO}_{3}{ }^{-}$treatment compared with the treatment with only $\mathrm{CH}_{4}$ also imply that $\mathrm{NO}_{3}{ }^{-}$had an enhancing effect on $\mathrm{CH}_{4}$ oxidation (Fig. 7). Supporting this, $\mathrm{NO}_{\mathrm{x}}^{-}$was present (Fig. S2B), and our previous stable isotope study also indicated active denitrification in the water column of AlinenMustajärvi (Tiirola et al. 2011). Furthermore, the Methylococcales MAGs, which were most abundant below the oxycline in Alinen-Mustajärvi, had genetic potential for partial denitrification (Fig. 6C). This suggests that boreal lake MOBs can potentially couple $\mathrm{NO}_{\mathrm{x}}{ }^{-}$reduction with $\mathrm{CH}_{4}$ oxidation. Despite our efforts to prevent $\mathrm{O}_{2}$ contamination, we cannot completely rule out the possibility that trace amounts of $\mathrm{O}_{2}$ diffused to incubation bottles through or out of the septa (since $\mathrm{O}_{2}$ can be trapped within septa during sample preparations) during the incubations (De Brabandere et al. 2012). Therefore, more rigorous measures to prevent $\mathrm{O}_{2}$ contamination are needed in future studies to resolve whether $\mathrm{NO}_{\mathrm{x}}{ }^{-}$reduction of MOBs was coupled with micro-aerobic $\mathrm{CH}_{4}$ activation (Kits et al. 2015b, Padilla et al. 2017) or with AOM that is independent of external $\mathrm{O}_{2}$, e.g. via a similar mechanism to that carried out by bacteria in NC10 phyla (Ettwig et al. 2010).

The lack of $\mathrm{SO}_{4}{ }^{2-}$-induced $\mathrm{CH}_{4}$ oxidation by MOBs was expected based on previous studies (Oswald et al. 2015, 2016b). In contrast, results on $\mathrm{Fe}^{3+}$ and $\mathrm{Mn}^{4+}$ were not expected, since both of them enhanced the activity of Methylococcales in the temperate Lake Zug, Switzerland (Oswald et al. 2016b), while Fe $\mathrm{Fe}^{3+}$ was also suggested to enhance $\mathrm{CH}_{4}$ oxidation by a mixed MOB-methanogen community in deep sediments of Lake Kinneret (Bar-Or et al. 2017). Accordingly, the decrease in $\mathrm{CH}_{4}$ oxidation by organic EAs was unexpected, as humic substances act as electron shuttles between $\mathrm{Fe}^{3+}\left(\mathrm{Mn}^{4+}\right)$ and bacteria (Lovley et al. 1996), and the capability for $\mathrm{Fe}^{3+} / \mathrm{Mn}^{4+}$ and organic EA respiration usually occur in the same species (Lovley 2006). However, despite decreasing the potential $\mathrm{CH}_{4}$ oxidation, the addition of inorganic EAs actually increased the relative pmoA expression of the Methylobacter MOBs that dominated in situ (Fig. 2C). Furthermore, the inorganic EA-induced decrease in the $\mathrm{CH}_{4}$ oxidation in the hypolimnion was actually very modest compared to other treatments, also coinciding with an increase in the relative abundance of in situ dominant MOB 16S rRNA (Fig. 2, Table 2). This implies that the metabolism of the in situ dominant MOBs in Mekkojärvi was enhanced by inorganic EAs; however, their effect on total potential $\mathrm{CH}_{4}$ oxidation was probably masked by the decrease in methanogen trace methane oxidation as explained 
above, as well as by the effect of other, naturally rare MOBs, which became prevalent and active during the incubation (Fig. 2B,C). Thus, further studies are still needed to assess the effect of EAs on $\mathrm{CH}_{4}$ oxidation of in situ dominant MOBs in boreal lakes. These studies could utilize specific inhibitors for the activity of methanogenic archaea and MOBs to distinguish between different $\mathrm{CH}_{4}$-oxidizing processes (Miller et al. 1998, Liu et al. 2011) as well as have a shorter incubation time than in this study to prevent the increase and activity of the undesired, naturally rare MOBs. A culture-dependent study approach (i.e. experiments with isolated lake MOBs) could be also adopted. It is also possible that the quality (e.g. oxidation state) of the utilized organic EAs differed from that of the organic EAs present in boreal lakes to an extent that would make them less usable for the lake microbes. Indeed, native oxidized organic matter was recently shown to increase bacterial activity in lake water columns (Lau et al. 2017). Therefore, further studies should also assess the effects of in situ organic EAs on MOB metabolism.

The dominance and vertical distribution patterns of the putative novel MOB lineage Ca. Methyloumidiphilus alinensis suggests that it played a very important role in water column $\mathrm{CH}_{4}$ oxidation in AlinenMustajärvi (Figs. 1D,E \& 3A). It belongs to MOB Type Ib (Figs. 5 \& S9), a group that was previously considered to consist only of species that are adapted to thermal habitats (Danilova et al. 2016). However, our findings and recent isolation of Methyloterricola oryzae from stems of rice plants and enrichment of Ca. Methylospira palustris from peat bog together with the discovery of $p m o A$ sequences that are closely related to these lineages from various non-thermal habitats have now changed this view (Danilova et al. 2016, Frindte et al. 2017). These results also suggest that there are even more undiscovered MOB Type Ib genera inhabiting non-thermal habitats. We actually noticed that $16 \mathrm{~S}$ rRNA gene sequences from Ca. M. alinensis were assigned as 'unclassified Gammaproteobacteria' when using older Silva 119 (released 24 July 2014) and 123 (23 July 2015) databases, which suggests that previous 16S rRNA amplicon-based studies might have failed to assign members of this lineage to MOBs. Therefore, we supplemented the utilized Silva 128 database with the clone library sequence representing Ca. M. alinensis (HE616416) and made a preliminary screening for this lineage from a set of 16S rRNA gene amplicon libraries from water column samples of oxygen-stratified lakes. Besides the study lakes, Ca. M. alinensis was detected in Lakes Valkea-Kotinen and Valkea-Mustajärvi in Fin- land (Peura et al. 2012), Lakes 227 and 442 in Canada (Schiff et al. 2017), Lake Grosse Fuchskuhle in Germany (Garcia et al. 2013), and Lake Rotsee in Switzerland (Oswald et al. 2017). However, it had much lower relative abundance $(0.0004$ to $0.7 \%$ of bacterial $16 \mathrm{~S}$ rRNA genes) in the other lakes compared with Alinen-Mustajärvi (up to $14.6 \%$ ), which could be caused by database biases (i.e. insufficient representation of the sequence diversity of this lineage in the database). However, these results suggest that $C a$. M. alinensis is a common member of MOB communities in water columns of oxygen-stratified lakes. Further studies are needed to assess its importance in $\mathrm{CH}_{4}$ oxidation in different ecosystems as well as the factors affecting its activity and distribution. Our results from the 2 study lakes suggest that Ca. M. alinensis prefers microaerobic/anaerobic conditions. However, its distribution pattern is different from that of the other ubiquitous water-column MOB genus, Methylobacter, suggesting niche differentiation between these bacterial genera. The preference of Ca. M. alinensis for higher water column layers and its rarity in Mekkojärvi, as compared to Methylobacter, can be due to it being more competitive in higher redox conditions or higher light radiation than Methylobacter, since both ORP and PAR decreased with depth and were higher in microaerobic/anaerobic layers of Alinen-Mustajärvi compared with Mekkojärvi.

\section{CONCLUSION}

Accumulating evidence from this and previous studies now suggests almost exclusive dominance of aerobic MOBs in the methanotrophic community and activity both above and below the oxycline in the water column of oxygen-stratified methane-rich lakes in the boreal and temperate zones. Besides the typical MOB-genera (e.g. Methylobacter, Methylomonas, and Crenothrix), the putative novel MOB lineage Ca. Methyloumidiphilus alinensis, found in this study, may be an important member of the MOB community in the water columns of oxygen-stratified lakes and has probably been undetected as a MOB in many previous $16 \mathrm{~S}$ rRNA amplicon studies due to database biases. In contrast to MOBs, the activity of typical AOM bacteria (NC10 phyla) and archaea (ANME archaea) in lakes seems to be limited to sediments. The incubation results together with the detection of genetic denitrification potential in MAGs of MOBs also imply that $\mathrm{NO}_{\mathrm{x}}{ }^{-}$reduction may support micro-aerobic or even anaerobic $\mathrm{CH}_{4}$ oxidation activity of boreal lake MOBs. Furthermore, this study suggests that light- 
driven oxygenic photosynthesis potentially supports aerobic $\mathrm{CH}_{4}$ oxidation below the oxycline in boreal lakes, in accordance with results from temperate lakes. However, light radiation above a certain PAR limit may also inhibit MOB activity, as was also suggested by the vertical distribution of MOBs in the study lakes. Consequently, the projected water brownification that decreases light penetration, and therefore, oxygenic photosynthesis in lake water columns can either (1) decrease $\mathrm{CH}_{4}$ oxidation, (2) not affect it due to ascent of the oxycline and the $\mathrm{CH}_{4}$ oxidation layer, or (3) even increase it, due to the cessation of light inhibition of MOBs.

Acknowledgements. This work was supported by The Academy of Finland (Grants 136455 and 140964 to H.N., 286642 to A.J.R., 260797 to M.T. and 265902 to S.P.). We thank the staff at the Lammi Biological Station for helping in the field and in the laboratory. We also thank the 3 anonymous reviewers and the editor for constructive comments on the earlier versions of this article.

\section{LITERATURE CITED}

á Norði K, Thamdrup B (2014) Nitrate-dependent anaerobic methane oxidation in a freshwater sediment. Geochim Cosmochim Acta 132:141-150

Alawi M, Lipski A, Sanders T, Pfeiffer EM, Spieck E (2007) Cultivation of a novel cold-adapted nitrite oxidizing betaproteobacterium from the Siberian Arctic. ISME J 1: 256-264

Bar-Or I, Elvert M, Eckert W, Kushmaro A and others (2017) Iron-coupled anaerobic oxidation of methane performed by a mixed bacterial-archaeal community based on poorly reactive minerals. Environ Sci Technol 51: 12293-12301

Bastviken D, Cole J, Pace M, Tranvik L (2004) Methane emissions from lakes: dependence of lake characteristics, two regional assessments, and a global estimate. Global Biogeochem Cycles 18:GB4009

Bastviken D, Tranvik LJ, Downing JA, Crill PM, EnrichPrast A (2011) Freshwater methane emissions offset the continental carbon sink. Science 331:50

Beal EJ, House CH, Orphan VJ (2009) Manganese- and iron-dependent marine methane oxidation. Science 325: 184-187

Biderre-Petit C, Jézéquel D, Dugat-Bony E, Lopes F and others (2011) Identification of microbial communities involved in the methane cycle of a freshwater meromictic lake. FEMS Microbiol Ecol 77:533-545

Blazewicz SJ, Petersen DG, Waldrop MP, Firestone MK (2012) Anaerobic oxidation of methane in tropical and boreal soils: ecological significance in terrestrial methane cycling. J Geophys Res 117:G02033

Blees J, Niemann H, Wenk CB, Zopfi J and others (2014) Micro-aerobic bacterial methane oxidation in the chemocline and anoxic water column of deep south-Alpine Lake Lugano (Switzerland). Limnol Oceanogr 59:311-324

Boisvert S, Laviolette F, Corbeil J (2010) Ray: simultaneous assembly of reads from a mix of high-throughput se- quencing technologies. J Comput Biol 17:1519-1533

* Brand A, Bruderer H, Oswald K, Guggenheim C, Schubert CJ, Wehrli B (2016) Oxygenic primary production below the oxycline and its importance for redox dynamics. Aquat Sci 78:727-741

Conrad R (1999) Contribution of hydrogen to methane production and control of hydrogen concentrations in methanogenic soils and sediments. FEMS Microbiol Ecol 28:193-202

*Danilova OV, Suzina NE, van de Kamp J, Svenning MM, Bodrossy L, Dedysh SN (2016) A new cell morphotype among methane oxidizers: a spiral-shaped obligately microaerophilic methanotroph from northern low-oxygen environments. ISME J 10:2734-2743

* De Brabandere L, Thamdrup B, Revsbech NP, Foadi R (2012) A critical assessment of the occurrence and extend of oxygen contamination during anaerobic incubations utilizing commercially available vials. J Microbiol Methods 88:147-154

* Deutzmann JS, Stief P, Brandes J, Schink B (2014) Anaerobic methane oxidation coupled to denitrification is the dominant methane sink in a deep lake. Proc Natl Acad Sci USA 111:18273-18278

* Downing JA, Prairie YT, Cole JJ, Duarte CM and others (2006) The global abundance and size distribution of lakes, ponds, and impoundments. Limnol Oceanogr 51: 2388-2397

* Dumestre JF, Guézennec J, Galy-Lacaux C, Delmas R, Richard S, Labroue L (1999) Influence of light intensity on methanotrophic bacterial activity in Petit Saut Reservoir, French Guiana. Appl Environ Microbiol 65:534-539

* Dumont MG, Lüke C, Deng Y, Frenzel P (2014) Classification of $p m o A$ amplicon pyrosequences using BLAST and the lowest common ancestor method in MEGAN. Front Microbiol 5:34

Durbin R, Eddy S, Krogh A, Mitchison G (2002) Biological sequence analysis: probabilistic models of proteins and nucleic acids. Cambridge University Press, Cambridge

* Edgar RC, Haas BJ, Clemente JC, Quince C, Knight R (2011) UCHIME improves sensitivity and speed of chimera detection. Bioinformatics 27:2194-2200

Engelbrektson A, Kunin V, Wrighton KC, Zvenigorodsky N, Chen F, Ochman H, Hugenholtz P (2010) Experimental factors affecting PCR-based estimates of microbial species richness and evenness. ISME J 4:642-647

* Ettwig KF, Butler MK, Le Paslier D, Pelletier E and others (2010) Nitrite-driven anaerobic methane oxidation by oxygenic bacteria. Nature 464:543-548

Ettwig KF, Zhu B, Speth D, Keltjens JT, Jetten MSM, Kartal B (2016) Archaea catalyze iron-dependent anaerobic oxidation of methane. Proc Natl Acad Sci USA 113: 12792-12796

Finn RD, Tate J, Mistry J, Coggill PC and others (2007) The Pfam protein families database. Nucleic Acids Res 36: D281-D288

Finster K (2008) Microbiological disproportionation of inorganic sulfur compounds. J Sulfur Chem 29:281-292

* Fish JA, Chai B, Wang Q, Sun Y, Brown CT, Tiedje J, Cole J (2013) FunGene: the functional gene pipeline and repository. Front Microbiol 4:291

* Frindte K, Maarastawi SA, Lipski A, Hamacher J, Knief C (2017) Characterization of the first rice paddy cluster I isolate, Methyloterricola oryzae gen. nov., sp. nov. and amended description of Methylomagnum ishizawai. Int J Syst Evol Microbiol 67:4507-4514 
Garcia SL, Salka I, Grossart HP, Warnecke F (2013) Depthdiscrete profiles of bacterial communities reveal pronounced spatio-temporal dynamics related to lake stratification. Environ Microbiol Rep 5:549-555

Gibson CE (1985) Growth rate, maintenance energy and pigmentation of planktonic Cyanophyta during one-hour light:dark cycles. Br Phycol J 20:155-161

* Griffiths RI, Whiteley AS, O'Donnell AG, Bailey MJ (2000) Rapid method for coextraction of DNA and RNA from natural environments for analysis of ribosomal DNA- and rRNA-based microbial community composition. Appl Environ Microbiol 66:5488-5491

Hanson RS, Hanson TE (1996) Methanotrophic bacteria. Microbiol Rev 60:439-471

* Haroon MF, Hu S, Shi Y, Imelfort M and others (2013) Anaerobic oxidation of methane coupled to nitrate reduction in a novel archaeal lineage. Nature 500:567-570

Hausmann B, Knorr KH, Schreck K, Tringe SG, Glavina del Rio T, Loy A, Pester M (2016) Consortia of low-abundance bacteria drive sulfate reduction-dependent degradation of fermentation products in peat soil microcosms. ISME J 10:2365-2375

KHedrich S, Schlömann M, Johnson DB (2011) The iron-oxidizing proteobacteria. Microbiology 157:1551-1564

Heising S, Richter L, Ludwig W, Schink B (1999) Chlorobium ferrooxidans sp. nov., a phototrophic green sulfur bacterium that oxidizes ferrous iron in coculture with a 'Geospirillum' sp. strain. Arch Microbiol 172:116-124

*Hong S, Bunge J, Leslin C, Jeon S, Epstein SS (2009) Polymerase chain reaction primers miss half of rRNA microbial diversity. ISME J 3:1365-1373

* Houser JN, Bade DL, Cole JJ, Pace ML (2003) The dual influences of dissolved organic carbon on hypolimnetic metabolism: organic substrate and photosynthetic reduction. Biogeochemistry 64:247-269

Huse SM, Welch DM, Morrison HG, Sogin ML (2010) Ironing out the wrinkles in the rare biosphere through improved OTU clustering. Environ Microbiol 12:1889-1898

Kalyuzhnaya MG, Yang S, Rozova ON, Smalley NE and others (2013) Highly efficient methane biocatalysis revealed in a methanotrophic bacterium. Nat Commun 4:2785

Kang DD, Froula J, Egan R, Wang Z (2015) MetaBAT, an efficient tool for accurately reconstructing single genomes from complex microbial communities. PeerJ 3:e1165

Kankaala P, Huotari J, Peltomaa E, Saloranta T, Ojala A (2006) Methanotrophic activity in relation to methane efflux and total heterotrophic bacterial production in a stratified, humic, boreal lake. Limnol Oceanogr 51: 1195-1204

Kankaala P, Taipale S, Nykänen H, Jones RI (2007) Oxidation, efflux, and isotopic fractionation of methane during autumnal turnover in a polyhumic, boreal lake. J Geophys Res 112:G02003

Karhunen J, Arvola L, Peura S, Tiirola M (2013) Green sulphur bacteria as a component of the photosynthetic plankton community in small dimictic humic lakes with an anoxic hypolimnion. Aquat Microb Ecol 68:267-272

Kirk JTO (1983) Light and photosynthesis in aquatic ecosystems. Cambridge University Press, Cambridge

Kirschke S, Bousquet P, Ciais P, Saunois M and others (2013) Three decades of global methane sources and sinks. Nat Geosci 6:813-823

Kits KD, Campbell DJ, Rosana AR, Stein LY (2015a) Diverse electron sources support denitrification under hypoxia in the obligate methanotroph Methylomicrobium album strain BG8. Front Microbiol 6:1072

Kits KD, Klotz MG, Stein LY (2015b) Methane oxidation coupled to nitrate reduction under hypoxia by the Gammaproteobacterium Methylomonas denitrificans, sp. nov. type strain FJG1. Environ Microbiol 17:3219-3232

Knittel K, Boetius A (2009) Anaerobic oxidation of methane: progress with an unknown process. Annu Rev Microbiol 63:311-334

Kortelainen P (1993) Content of total organic carbon in Finnish lakes and its relationship to catchment characteristics. Can J Fish Aquat Sci 50:1477-1483

Kuever J (2014) The family Desulfobulbaceae. In: Rosenberg E, DeLong EF, Lory S, Stackebrandt E, Thompson F (eds) The prokaryotes: Deltaproteobacteria and Epsilonproteobacteria. Springer, Berlin, p 75-86

* Langmead B, Salzberg SL (2012) Fast gapped-read alignment with Bowtie 2. Nat Methods 9:357-359

* Lau MP, Hupfer M, Grossart HP (2017) Reduction-oxidation cycles of organic matter increase bacterial activity in the pelagic oxycline. Environ Microbiol Rep 9:257-267

Liu H, Wang J, Wang A, Chen J (2011) Chemical inhibitors of methanogenesis and putative applications. Appl Microbiol Biotechnol 89:1333-1340

* Lovley DR (2006) Dissimilatory Fe(III)- and Mn(IV)-reducing prokaryotes. The Prokaryotes 2:635-658

Lovley DR, Coates JD, Blunt-Harris E, Phillips EJP, Woodward JC (1996) Humic substances as electron acceptors for microbial respiration. Nature 382:445-448

Martinez-Cruz K, Leewis MC, Herriott IC, SepulvedaJauregui A, Anthony KW, Thalasso F, Leigh MB (2017) Anaerobic oxidation of methane by aerobic methanotrophs in sub-Arctic lake sediments. Sci Total Environ 607-608:23-31

* Menzel P, Ng KL, Krogh A (2016) Fast and sensitive taxonomic classification for metagenomics with Kaiju. Nat Commun 7:11257

*Meulepas RJW, Jagersma CG, Zhang Y, Petrillo M and others (2010) Trace methane oxidation and the methane dependency of sulfate reduction in anaerobic granular sludge. FEMS Microbiol Ecol 72:261-271

* Milferstedt K, Youngblut ND, Whitaker RJ (2010) Spatial structure and persistence of methanogen populations in humic bog lakes. ISME J 4:764-776

* Miller LG, Sasson C, Oremland RS (1998) Difluoromethane, a new and improved inhibitor of methanotrophy. Appl Environ Microbiol 64:4357-4362

* Milucka J, Kirf M, Lu L, Krupke A and others (2015) Methane oxidation coupled to oxygenic photosynthesis in anoxic waters. ISME J 9:1991-2002

*Moran JJ, House CH, Freeman KH, Ferry JG (2005) Trace methane oxidation studied in several Euryarchaeota under diverse conditions. Archaea 1:303-309

* Moya-Beltrán A, Cárdenas JP, Covarrubias PC, Issotta F and others (2014) Draft genome sequence of the nominated type strain of 'Ferrovum myxofaciens,' an acidophilic, iron-oxidizing betaproteobacterium. Genome Announc 2:e00834-14

Murase J, Sugimoto A (2005) Inhibitory effect of light on methane oxidation in the pelagic water column of a mesotrophic lake (Lake Biwa, Japan). Limnol Oceanogr 50:1339-1343

火 Nykänen H, Peura S, Kankaala P, Jones RI (2014) Recycling and fluxes of carbon gases in a stratified boreal lake following experimental carbon addition. Biogeosciences Discuss 11:16447-16495 
Ojala A, Bellido JL, Tulonen T, Kankaala P, Huotari J (2011) Carbon gas fluxes from a brown-water and a clear-water lake in the boreal zone during a summer with extreme rain events. Limnol Oceanogr 56:61-76

Oswald K, Milucka J, Brand A, Littmann S, Wehrli B, Kuypers MMM, Schubert CJ (2015) Light-dependent aerobic methane oxidation reduces methane emissions from seasonally stratified lakes. PLOS ONE 10:e0132574

* Oswald K, Jegge C, Tischer J, Berg J and others (2016a) Methanotrophy under versatile conditions in the water column of the ferruginous meromictic Lake La Cruz (Spain). Front Microbiol 7:1762

* Oswald K, Milucka J, Brand A, Hach P and others (2016b) Aerobic gammaproteobacterial methanotrophs mitigate methane emissions from oxic and anoxic lake waters. Limnol Oceanogr 61:S101-S118

Oswald K, Graf JS, Littmann S, Tienken D and others (2017) Crenothrix are major methane consumers in stratified lakes. ISME J 11:2124-2140

Padilla CC, Bertagnolli AD, Bristow LA, Sarode N, Glass JB, Thamdrup B, Stewart FJ (2017) Metagenomic binning recovers a transcriptionally active Gammaproteobacterium linking methanotrophy to partial denitrification in an anoxic oxygen minimum zone. Front Mar Sci 4:23

Parks DH, Imelfort M, Skennerton CT, Hugenholtz P, Tyson GW (2015) CheckM: assessing the quality of microbial genomes recovered from isolates, single cells, and metagenomes. Genome Res 25:1043-1055

Peura S, Eiler A, Bertilsson S, Nykanen H, Tiirola M, Jones RI (2012) Distinct and diverse anaerobic bacterial communities in boreal lakes dominated by candidate division OD1. ISME J 6:1640-1652

Peura S, Sinclair L, Bertilsson S, Eiler A (2015) Metagenomic insights into strategies of aerobic and anaerobic carbon and nitrogen transformation in boreal lakes. Sci Rep 5: 12102

Postgate JR, Campbell LL (1966) Classification of Desulfovibrio species, the non-sporulating sulfate-reducing bacteria. Bacteriol Rev 30:732-738

Quinlan AR, Hall IM (2010) BEDTools: a flexible suite of utilities for comparing genomic features. Bioinformatics 26:841-842

Rinke C, Schwientek P, Sczyrba A, Ivanova NN and others (2013) Insights into the phylogeny and coding potential of microbial dark matter. Nature 499:431-437

Rissanen AJ, Karvinen A, Nykänen H, Peura S, Tiirola M, Mäki A, Kankaala P (2017) Effects of alternative electron acceptors on the activity and community structure of methane-producing and consuming microbes in the sediments of two shallow boreal lakes. FEMS Microbiol Ecol 93:fix078

Salonen K, Arvola L, Rask M (1984) Autumnal and vernal circulation of small forest lakes in southern Finland. Verh Int Ver Theor Angew Limnol 22:103-107

Scheller S, Yu H, Chadwick GL, McGlynn SE, Orphan VJ (2016) Artificial electron acceptors decouple archaeal methane oxidation from sulfate reduction. Science 351: 703-707

Schiff SL, Tsuji JM, Wu L, Venkiteswaran JJ and others (2017) Millions of boreal shield lakes can be used to probe Archaean Ocean biogeochemistry. Sci Rep 7: 46708

Schloss PD, Westcott SL, Ryabin T, Hall JR and others (2009) Introducing mothur: open-source, platform-independent, community-supported software for describing and comparing microbial communities. Appl Environ Microbiol $75: 7537-7541$

Seemann T (2014) Prokka: rapid prokaryotic genome annotation. Bioinformatics 30:2068-2069

* Segata N, Bornigen D, Morgan XC, Huttenhower C (2013) PhyloPhlAn is a new method for improved phylogenetic and taxonomic placement of microbes. Nat Commun 4: 2304

Selengut JD, Haft DH, Davidsen T, Ganapathy A and others (2007) TIGRFAMs and genome properties: tools for the assignment of molecular function and biological process in prokaryotic genomes. Nucleic Acids Res 35: D260-D264

* Sivan O, Adler M, Pearson A, Gelman F, Bar-Or I, John SG, Eckert W (2011) Geochemical evidence for iron-mediated anaerobic oxidation of methane. Limnol Oceanogr 56:1536-1544

Taipale S, Jones RI, Tiirola M (2009) Vertical diversity of bacteria in an oxygen-stratified humic lake, evaluated using DNA and phospholipid analyses. Aquat Microb Ecol 55:1-16

Tamura K, Stecher G, Peterson D, Filipski A, Kumar S (2013) MEGA6: Molecular Evolutionary Genetics Analysis version 6.0. Mol Biol Evol 30:2725-2729

Tiirola MA, Rissanen AJ, Sarpakunnas M, Arvola L, Nykänen H (2011) Stable isotope profiles of nitrogen gas indicate denitrification in oxygen-stratified humic lakes. Rapid Commun Mass Spectrom 25:1497-1502

Timmers PH, Suarez-Zuluaga DA, van Rossem M, Diender M, Stams AJ, Plugge CM (2016) Anaerobic oxidation of methane associated with sulfate reduction in a natural freshwater gas source. ISME J 10:1400-1412

*Timmers PHA, Welte CU, Koehorst JJ, Plugge CM, Jetten MS, Stams AJ (2017) Reverse methanogenesis and respiration in methanotrophic archaea. Archaea 2017: 1654237

Van Gemerden H, Mas J (1995) Ecology of phototrophic sulfur bacteria. In: Blankenship RE, Madigan MT, Bauer CE (eds) Anoxygenic photosynthetic bacteria. Springer, Dordrecht, p 49-85

*Verpoorter C, Kutser T, Seekell DA, Tranvik LJ (2014) A global inventory of lakes based on high-resolution satellite imagery. Geophys Res Lett 41:6396-6402

*Wang Q, Garrity GM, Tiedje JM, Cole JR (2007) Naïve Bayesian classifier for rapid assignment of rRNA sequences into the new bacterial taxonomy. Appl Environ Microbiol 73:5261-5267

Wang Q, Quensen JF, Fish JA, Kwon Lee T, Sun Y, Tiedje JM, Cole JR (2013) Ecological patterns of nifH genes in four terrestrial climatic zones explored with targeted metagenomics using FrameBot, a new informatics tool. MBio 4:e00592-13

Whiticar MJ (1999) Carbon and hydrogen isotope systematics of bacterial formation and oxidation of methane. Chem Geol 161:291-314

Wik M, Varner RK, Anthony KW, MacIntyre S, Bastviken D (2016) Climate-sensitive northern lakes and ponds are critical components of methane release. Nat Geosci 9: 99-105

Koungblut ND, Dell'Aringa M, Whitaker RJ (2014) Differentiation between sediment and hypolimnion methanogen communities in humic lakes. Environ Microbiol 16: $1411-1423$

Submitted: August 24, 2017; Accepted: April 18, 2018

Proofs received from author(s): May 18, 2018 